\title{
Topical drug delivery devices: A review
}

Citation for published version (APA):

Bertens, C. J. F., Gijs, M., van den Biggelaar, F. J. H. M., \& Nuijts, R. M. M. A. (2018). Topical drug delivery devices: A review. Experimental Eye Research, 168, 149-160.

https://doi.org/10.1016/j.exer.2018.01.010

Document status and date:

Published: 01/03/2018

DOI:

10.1016/j.exer.2018.01.010

Document Version:

Publisher's PDF, also known as Version of record

Document license:

Taverne

\section{Please check the document version of this publication:}

- A submitted manuscript is the version of the article upon submission and before peer-review. There can be important differences between the submitted version and the official published version of record.

People interested in the research are advised to contact the author for the final version of the publication, or visit the DOI to the publisher's website.

- The final author version and the galley proof are versions of the publication after peer review.

- The final published version features the final layout of the paper including the volume, issue and page numbers.

Link to publication

\footnotetext{
General rights rights.

- You may freely distribute the URL identifying the publication in the public portal. please follow below link for the End User Agreement:

www.umlib.nl/taverne-license

Take down policy

If you believe that this document breaches copyright please contact us at:

repository@maastrichtuniversity.nl

providing details and we will investigate your claim.
}

Copyright and moral rights for the publications made accessible in the public portal are retained by the authors and/or other copyright owners and it is a condition of accessing publications that users recognise and abide by the legal requirements associated with these

- Users may download and print one copy of any publication from the public portal for the purpose of private study or research.

- You may not further distribute the material or use it for any profit-making activity or commercial gain

If the publication is distributed under the terms of Article $25 \mathrm{fa}$ of the Dutch Copyright Act, indicated by the "Taverne" license above, 


\title{
Topical drug delivery devices: A review
}

\author{
Christian J.F. Bertens ${ }^{\mathrm{a}, \mathrm{b}, \mathrm{c}, *}$, Marlies Gijs ${ }^{\mathrm{a}, \mathrm{b}, \mathrm{c}}$, Frank J.H.M. van den Biggelaar ${ }^{\mathrm{a}, \mathrm{c}}$, \\ Rudy M.M.A. Nuijts ${ }^{\mathrm{a}, \mathrm{c}}$

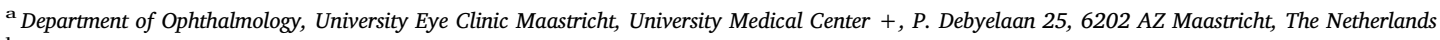 \\ ${ }^{\mathrm{b}}$ Department of Neuroscience, School for Mental Health and Neuroscience (MHeNS), Maastricht University, Universiteitssingel 50, 6229 ER Maastricht, The Netherlands \\ ${ }^{c}$ Chemelot Institute for Science and Technology (InSciTe), Urmonderbaan 20F, 6167 RD Geleen, The Netherlands
}

\section{A R T I C L E I N F O}

\section{Keywords:}

Ophthalmic drug delivery

Eye drop replacement

Patient compliance

Drug delivery routes

Ocular inserts

Ophthalmic drug delivery devices

\begin{abstract}
A B S T R A C T
For the treatment and prevention of ocular diseases, most patients are treated with conventional drug delivery formulations such as eye drops or ointments. However, eye drops and ointments suffer from low patient compliance and low effective drug concentration at the target site. Therefore, new medical devices are being explored to improve drug delivery to the eye. Over the years, various delivery devices have been developed including resorbable devices, oval- and ring-shaped devices, rod-shaped devices, punctum plugs, contact lenses and corneal shields. Only a few devices (eg. Mydriasert ${ }^{\circ}$, Ozurdex ${ }^{\circ}$, Surodex ${ }^{\circ}$, Iluvien ${ }^{\circ}$, Lacrisert ${ }^{\circ}$ and Retisert ${ }^{\circ}$ ) have made it to the market while others are being investigated in clinical trials.

Altogether, there is a need for enhanced topical drug delivery. Only by working together (academia, industry and authorities) and by exploring parallel strategies (new drug delivery devices, enhanced drug formulations, better understanding of the pharmacokinetic properties), the therapeutic effect of drug treatments can be improved.
\end{abstract}

\section{Introduction}

Due to the increased prevalence of ocular diseases in the aging population (such as presbyopia, cataract, dry eyes and glaucoma), there is an increased demand for treatment of eye diseases. Aging of the lens may lead to loss of accommodation (presbyopia) or protein aggregation (cataract). Although revolutionary treatments have been discovered, for example lipoic acid (LA) to prevent the loss of accommodation (Garner and Garner, 2016), compound 29 and lanosterol to restore lens transparency in (congenital) cataract (Makley et al., 2015; Zhao et al., 2015) or Kinostat ${ }^{\circledR}$ to prevent cataract in diabetic dogs (Kador et al., 2014), they mostly require life-long or long-term administration of eye drops. Also, ocular therapies for dry eyes consist of life-long topical administered artificial tears, gels, ointments or lubricants to relieve symptoms (Pucker et al., 2016). Glaucoma therapy consists of topical applied beta blockers or prostaglandin analogs, laser therapy or surgery to lower the intra ocular pressure (IOP) (Jonas et al., 2017; Lavia et al., 2017; Trese et al., 2017).

Ocular surgeries range from routine cataract extraction and lens implantation, the most commonly performed surgery worldwide, to rarely performed surgeries such as keratoprosthesis. Due to an increase in the number of surgeries, the odds of infections and inflammations increase if postoperative care is not taken care of properly. A variety of postoperative complications may occur such as cystoid macular edema (CME) (incidence 1.2\%-3.5\%) after cataract surgery (Jick, 2016; Shah et al., 2016; Wielders et al., 2017). In order to prevent postoperative complications, patients are treated with ophthalmic anti-inflammatory drugs such as corticosteroids or non-steroidal anti-inflammatory drugs (NSAIDs), and antibiotics (Cantor et al., 2014; Kessel et al., 2014; Kim et al., 2015, 2016; Shah et al., 2016; Wielders et al., 2015, 2017).

In all ocular therapies and surgeries involving medicines, the route of drug delivery plays an important role. Although systemic drugs do reach the ocular tissues (Vellonen et al., 2016), high doses are required which often lead to side effects. Therefore, the most preferred way of

\footnotetext{
Abbreviations: Benzalkonium chloride, (BAC); Cystoid macular edema, (CME); Ethylenediaminetetraacetic acid, (EDTA); Ethylene-vinyl acetate, (EVA); Food and drug administration,

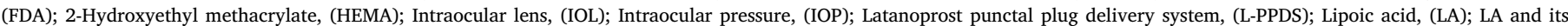

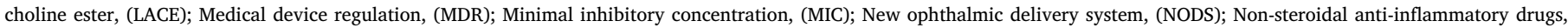

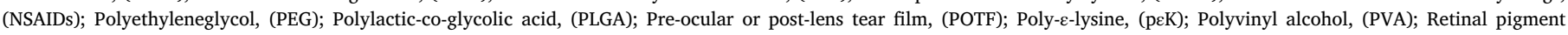

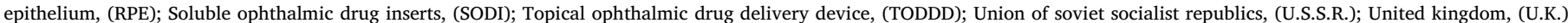

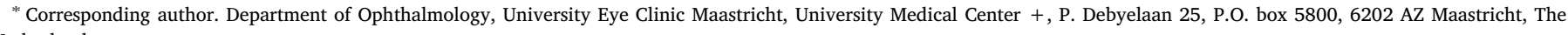
Netherlands.

E-mail addresses: Christian.Bertens@mumc.nl (C.J.F. Bertens), Marlies.Gijs@mumc.nl (M. Gijs), F.vanden.Biggelaar@mumc.nl (F.J.H.M. van den Biggelaar), Rudy.Nuijts@mumc.nl (R.M.M.A. Nuijts).
} 


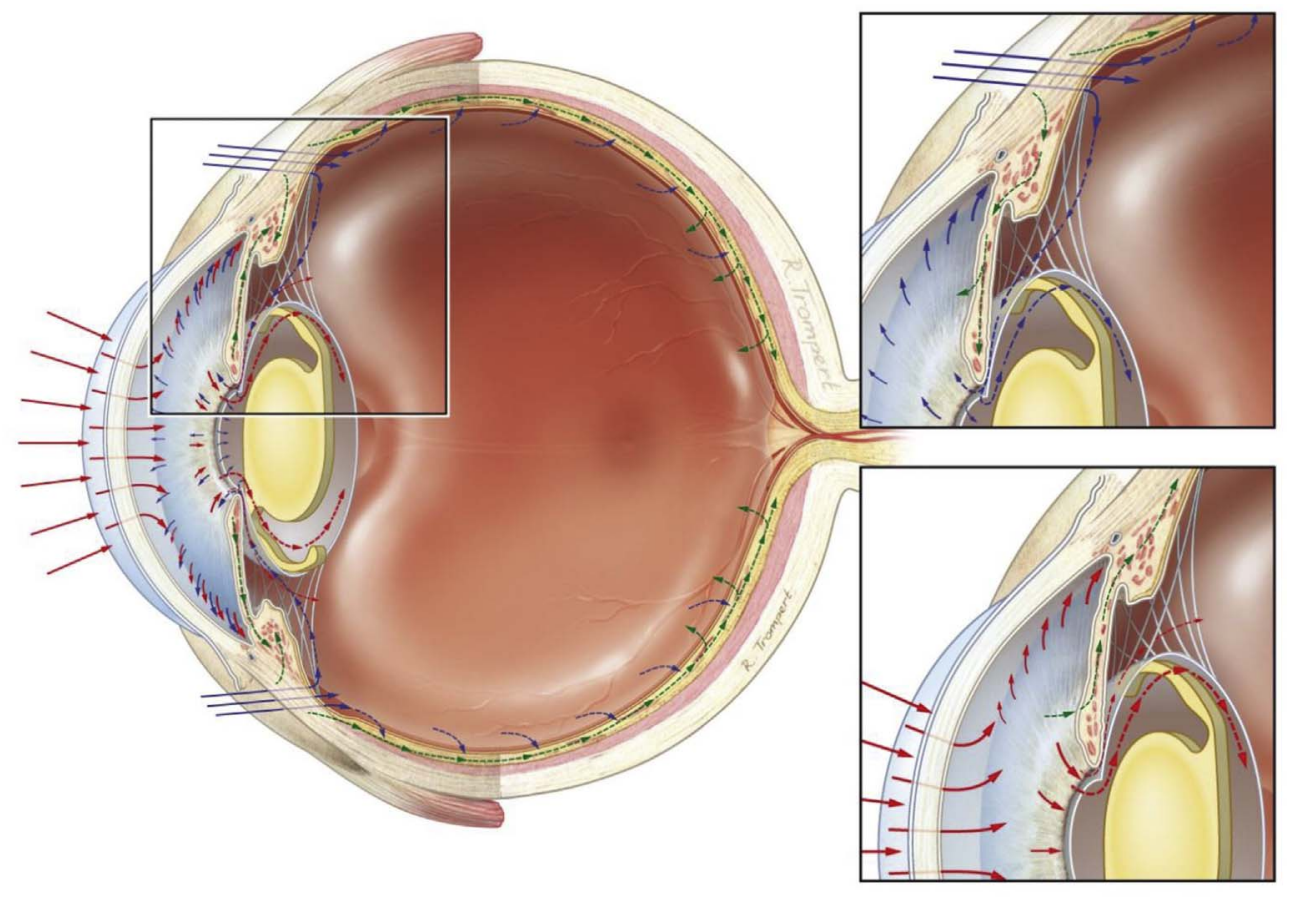

Fig. 1. Drug delivery routes in the eye.

Red arrows show the corneal delivery route with penetration through the cornea into the anterior chamber and clearance via the trabecular meshwork (anterior elimination route). A small part of the drug (dependent on the molecular weight and lipophilicity) will migrate into tissue of the iris or bind to the melanin pigment, from where it can get into the posterior chamber (green arrows). The lower inset shows a magnification of the corneal route.

Blue arrows show the non-corneal delivery route, drugs penetrate via the conjunctiva through the sclera into the choroid and to some extend through the retina into the vitreous cavity (green arrows). In the vitreous cavity, small drug molecules $(<2 \mathrm{~nm})$ will be cleared via the blood-retina barrier (posterior elimination route, blue arrows). Most of the drug will reach the anterior chamber via aqueous humor flow. The upper inset provides a magnification of the non-corneal drug delivery route and drug transport or diffusion into the anterior chamber.

The figure is drawn with an IOL to address that an IOL due to its anatomical position could be used as drug delivery system. (For interpretation of the references to colour in this figure legend, the reader is referred to the Web version of this article.) drug delivery to the eye is topically. Drugs administered topically are absorbed through the corneal or non-corneal absorption route (Fig. 1). Drug molecules with high corneal permeability (eg. small molecules with a hydroxyl group) prefer the corneal route (Fig. 1) (Del Amo et al., 2017; Edward and Prausnitz, 2001). This route starts with passive diffusion of drug molecules via the epithelium, through the stroma and endothelium into the anterior chamber, where the drug will exert its pharmacological function (Edward and Prausnitz, 2001; Ho et al., 2014; Shikamura et al., 2016; Zhang et al., 2004) or bind to the melanin pigment in the iris and ciliary body (Agrahari et al., 2016) or to plasma proteins (Pelkonen et al., 2017) to prolong its pharmacological function. Remaining drugs and drug waste products will be cleared via the trabecular meshwork through Schlemm's channel into the systemic blood circulation (conventional pathway) or via the iris to the uveoscleral tissue (unconventional pathway) and subsequently into the systemic blood circulation (Carreon et al., 2017; Del Amo and Urtti, 2015; Goel et al., 2010; Loewen et al., 2016). A minor part of the drug (dependent on the molecular weight and lipophilicity) will reach the posterior chamber via penetration of the iris and diffusion via the aqueous humor flow resulting in drug concentrations in the vitreous which are 10 and 100 times less than in the aqueous humor and cornea, respectively (Del Amo et al., 2017). It must be noted that these pharmacokinetics can be altered due to eye rotations (Bonfiglio et al., 2015; Stocchino et al., 2007) and ocular diseases (Guo et al., 2017; Ho et al., 2014; Li et al., 2016).

Drugs with low corneal permeability (eg. large molecules and proteins) will penetrate the eye via the conjunctiva and/or the sclera, the so-called non-corneal absorption route (Fig. 2) (Ambati et al., 2000; Bauer et al., 1999b; Del Amo and Urtti, 2015; Hughes et al., 2005; Lee et al., 2008). This route delivers drugs to the vitreous cavity via passive diffusion. Moreover, it is hypothesized that active transport also plays a role. Drugs penetrate or diffuse via the conjunctiva through the sclera into the choroid and through the retina (retinal pigment epithelium (RPE) cells and retinal capillary endothelial cells) into the vitreous cavity (Ahmed and Patton, 1985; Kim et al., 2004; Shikamura et al., 2016; Zhang et al., 2004). Once inside the vitreous chamber the drug will be transported towards the anterior chamber by the flow of aqueous humor or will be cleared via passive diffusion (determined by the LogD7.4 and hydrogen bonding capacity of the drug) by the RPE and retinal capillary endothelial cells (which form the blood-retinal barrier) through the choroidal circulation into the systemic blood flow (Del Amo et al., 2017; Del Amo and Urtti, 2015; Kidron et al., 2012). The non-corneal absorption route delivers 20 times lower drug concentration into the anterior chamber compared to the corneal absorption route (Ahmed and Patton, 1985).

Conventional ocular dosage forms, such as eye drop solutions (Fig. 2,10) and ointments, account for approximately $90 \%$ of currently marketed ophthalmic pharmaceuticals. Their biggest advantages are ease of administration and low costs. Moreover, eye drops are well accepted by most patients and have a rapid and localized drug action (Lang, 1995). Nevertheless, eye drop delivery is associated with several disadvantages. Next to systemic side effects (Farkouh et al., 2016) and toxicity (Palmer and Kaufman, 1995), the main disadvantages of eye drop delivery are low drug bioavailability and poor patient compliance (Table 1). Pre-corneal loss of the drug (by systemic conjunctival elimination, blinking, induced lacrimation, the tear film and rapid tear turnover, see Table 1) results in a very low ocular bioavailability of the drug at its target destination. Typically, less than $5 \%$ of the total administered dose reaches the anterior chamber (Hughes et al., 2005; Lee et al., 2004; Urtti and Salminen, 1993). In addition, high aqueous humor turnover washes out the drugs relatively fast $(1.0 \%-1.5 \%$ of the anterior chamber volume per minute) (Goel et al., 2010; Lang, 1995), and drug-melanin binding could affect the pharmacological function of the drug (Del Amo et al., 2017; Pelkonen et al., 2017) (Table 1). Another excreting factor influencing pre-corneal loss is lacrimal clearance, which clears aqueous solutions in $60 \mathrm{~s}$ and higher viscose solutions such as hydroxypropyl methylcellulose in $4 \mathrm{~min}$ (depending on its concentration) (Linn and Jones, 1968).

In order to maintain minimum inhibitory concentrations, ocular drugs need to be administered frequently resulting in poor patient compliance (Hermann et al., 2010; Nordmann et al., 2010; Salyani and Birt, 2005) (Table 1). Low patient compliance is mainly caused by incorrect instillment (timewise and dropwise) of the eye drops, which typically occurs in more cases than assumed by physicians and patients (Eaton et al., 2015; Mohindroo et al., 2015; Newman-Casey et al., 2015; Nordmann et al., 2010) (Table 1). Low patient compliance may result in an increased incidence and severity of postoperative complications (such as inflammation) and under-treatment of ocular diseases (such as 


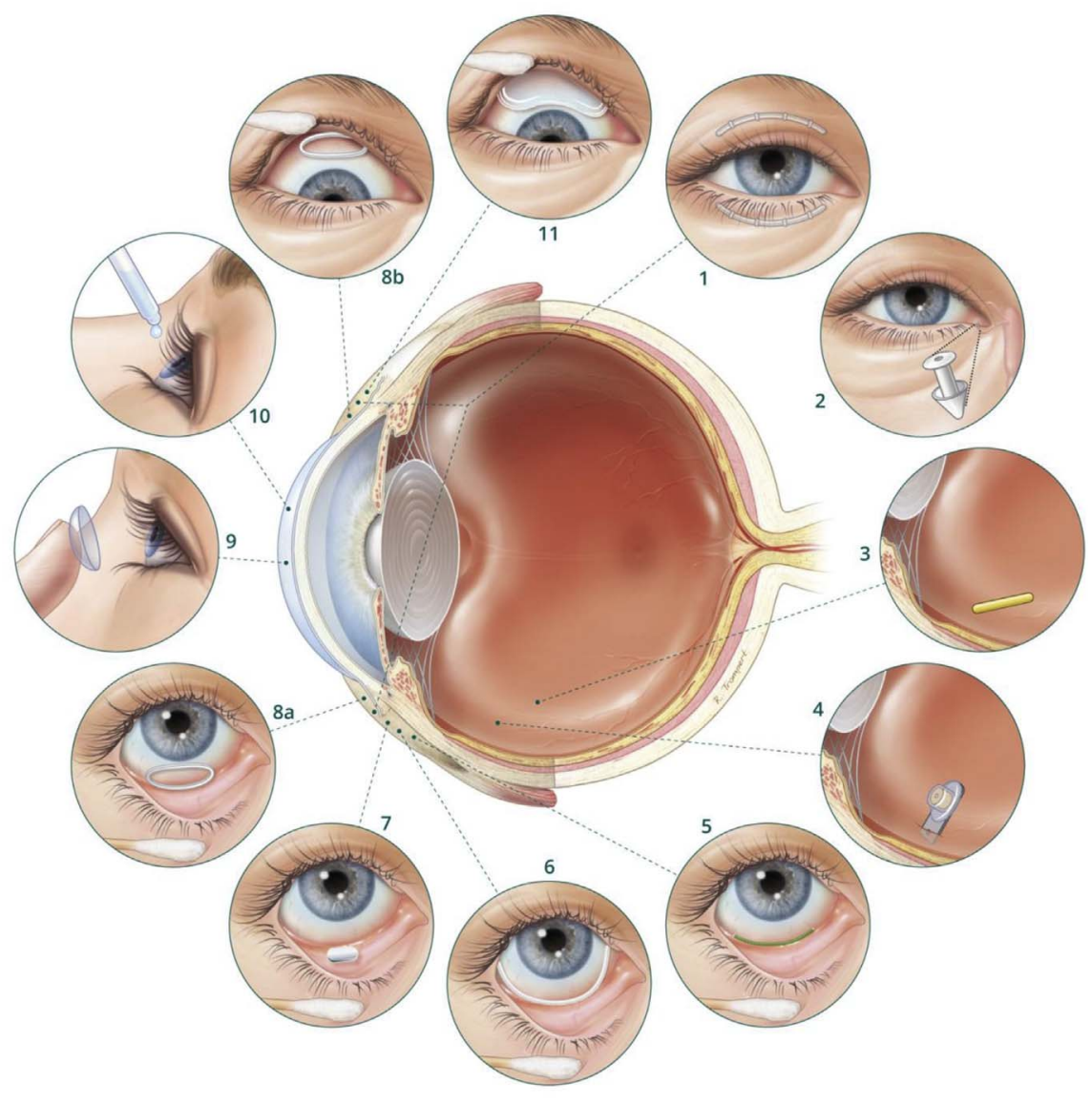

Fig. 2. Overview of drug delivery devices.

1. Conjunctival insert Ocufit $\mathrm{SR}^{\circ}$, which can be placed in both, the inferior and superior conjunctival fornix.

2. Punctum plug such as Dextenza or Evolute should be inserted in the inferior punctum.

3. Intravitreal insert such as Illuven ${ }^{*}$ or Surodex ${ }^{\circ}$ which are implanted or injected into the vitreous chamber.

4. Intravitreal insert Retrisert ${ }^{\circ}$, which is implanted into the vitreous chamber and is stitched to the sclera.

5. Conjunctival insert OphthaCoil, is a device placed behind the lower eyelid in the fornix of the conjunctiva.

6. Conjunctival insert Helios ${ }^{\mathrm{TM}}$. The ring is placed round the globe into the inferior and superior conjunctival fornix.

7. Conjunctival tablet, Lacrisert ${ }^{\circ}$ or Mydriasert ${ }^{\circ}$. Both tablets are placed in the inferior conjunctival fornix.

8. Conjunctival insert Ocusert ${ }^{\circ}$, can be placed in the inferior (8a) and superior $(8 \mathrm{~b})$ conjunctival fornix.

9. Contact lens for drug delivery, to be placed on the cornea. 10. Eye drops.

11. Conjunctival insert for the superior conjunctiva, TODDD ${ }^{\mathrm{TM}}$.
Table 1

Examples of disadvantages related to eye drops.

\begin{tabular}{ll}
\hline Disadvantage & Reference \\
\hline $\begin{array}{l}\text { Systemic side effects } \\
\text { Toxicity }\end{array}$ & $\begin{array}{l}\text { (Farkouh et al., 2016) } \\
\text { (Palmer and Kaufman, 1995) } \\
\text { Low ocular bioavailability: } \\
\text { Pre-corneal loss of the drug due to } \\
\text { systemic conjunctival elimination, } \\
\text { blinking, induced lacrimation, the tear } \\
\text { film and rapid tear turnover. }\end{array} \quad \begin{array}{l}\text { Lee et al., 2004; Urtti and } \\
\text { Salminen, 1985, 1993) }\end{array}$ \\
$\begin{array}{l}\text { Low ocular bioavailability: } \\
\text { Fast drug wash-out due to high aqueous } \\
\text { humor turnover or lacrimal clearance }\end{array}$ & (Goel et al., 2010; Lang, 1995; \\
Low ocular bioavailability: & \\
Drug binding to proteins & (Del Amo et al., 2017; Pelkonen \\
Poor patient compliance: & et al., 2017) \\
Drop instillment is (too) frequent & (Eaton et al., 2015; Mohindroo \\
& et al., 2015; Newman-Casey et al., \\
2015; Nordmann et al., 2010) \\
Poor patient compliance: & (Eaton et al., 2015; Mohindroo \\
Drop instillment is incorrectly & et al., 2015; Newman-Casey et al., \\
performed & 2015; Nordmann et al., 2010) \\
\hline
\end{tabular}

glaucoma), which create a significant burden for the health care system. Therefore, new methods for ocular drug delivery are needed within the ophthalmic field. In this review, an overview of current state of knowledge on topical drug delivery devices is provided.

\section{Topical drug delivery devices}

In response to the obstacles of conventional drug dosage forms, alternatives have been explored. These are mainly drug-loaded medical devices which use the non-corneal absorption route (Fig. 2). Historically, the first precursors of ocular inserts were small sections of filter paper impregnated with drug solutions (eg., atropine sulfate, pilocarpine hydrochloride) (Edman, 1993). In the late 1800s, polymeric inserts containing cocaine for local anesthesia were already used in the United Kingdom (U.K.) (Del Amo and Urtti, 2008). In the 1970s, soluble ophthalmic drug inserts (SODIs) were introduced in the Union of Soviet Socialist Republics (U.S.S.R.) (Maichuk, 1975b). SODIs were oval plates made from polyvinyl alcohol (PVA) and impregnated with several drugs. According to a trial in which 500 patients participated, SODIs had good tolerance (Maichuk, 1975a, b). So far, most drug delivery devices have been explored for posterior drug delivery (eg. intraocular pressure lowering drugs for glaucoma) and research has been primarily initiated by the industry. Only vitreous implants have made it to the market, as episcleral implants were not able to deliver enough drugs into the vitreous cavity (Kim et al., 2004; Li et al., 2016). A few vitreous implants are commercially available, including Ozurdex (Allergan inc., Irvine, California, USA) (Fig. 2,3) (0.7 mg dexamethasone for $60-90$ days), Surodex (Oculex Pharmaceuticals Inc. taken over by Allergan Inc., Irvine, California, USA in 2003) (60 $\mu$ g dexamethasone for 7-10 days), Iluvien (Alimera Sciences Inc., Alpharetta, Georgia, USA) (Fig. 2,3) (0.23-0.45 $\mu \mathrm{g}$ /day fluocinolone for 18-36 months) and Retisert ${ }^{\circ}$ (Bausch \& Lomb, Bridgewater, New Jersey, USA) (Fig. 2,4) $(0.59 \mathrm{mg}$ fluocinolone acetonide for 30 months). These devices are placed in the vitreous chamber by implantation or injection.

Today, there is also interest in exploring these devices for the anterior segment. However, it is difficult to create an implant for the anterior chamber, since it will move due to the low viscosity of the aqueous humor, and thereby causing irreversible damage to the endothelial cells (Bourne, 2003). Although, when Surodex (Allergan, Inc., Irvine, California, USA) was injected in the anterior chamber, it did not result in irreversible endothelial cell damage (Tan et al., 1999, 2001).

Another focus is on improving the bioavailability of ocular drugs 


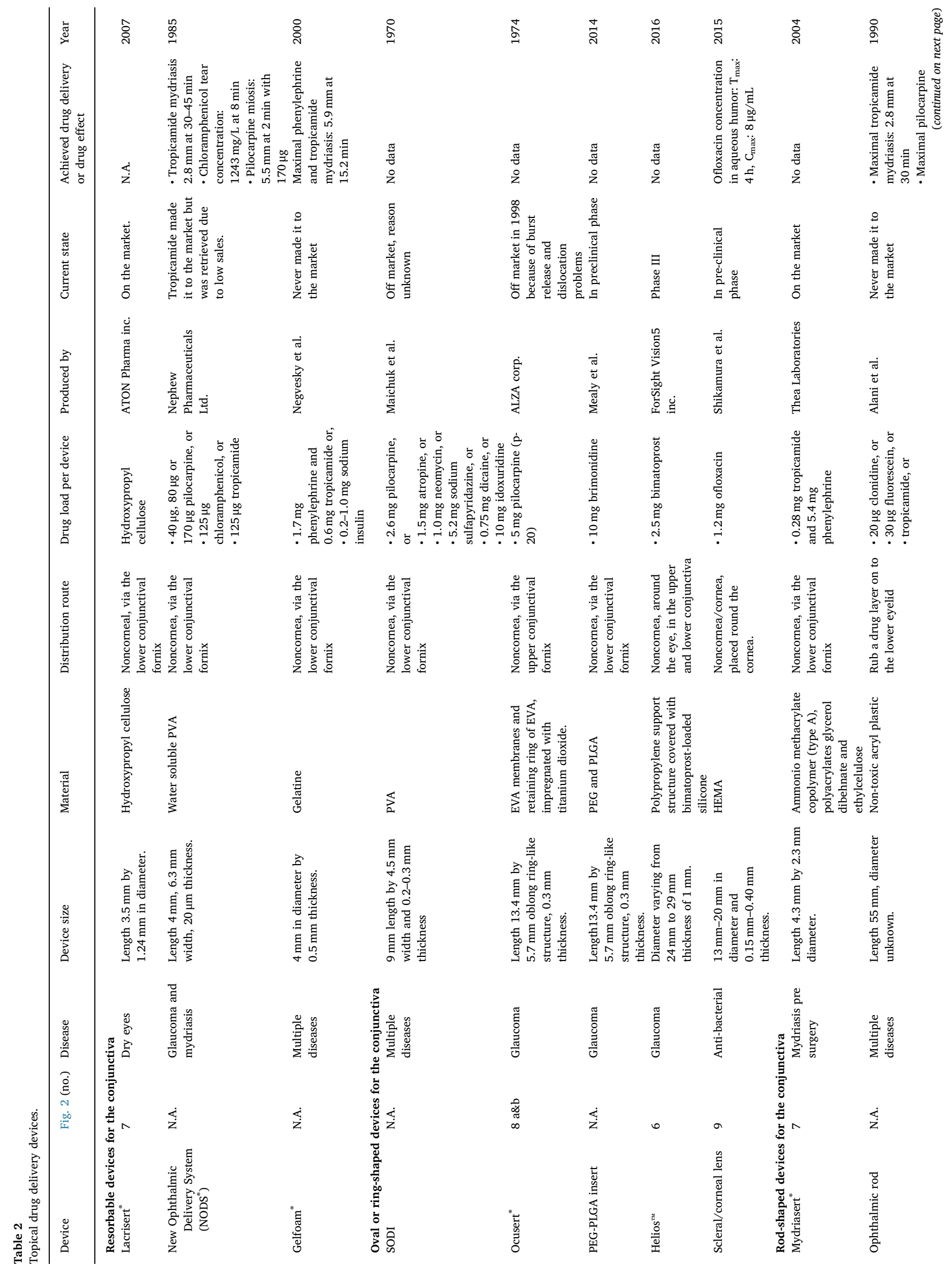




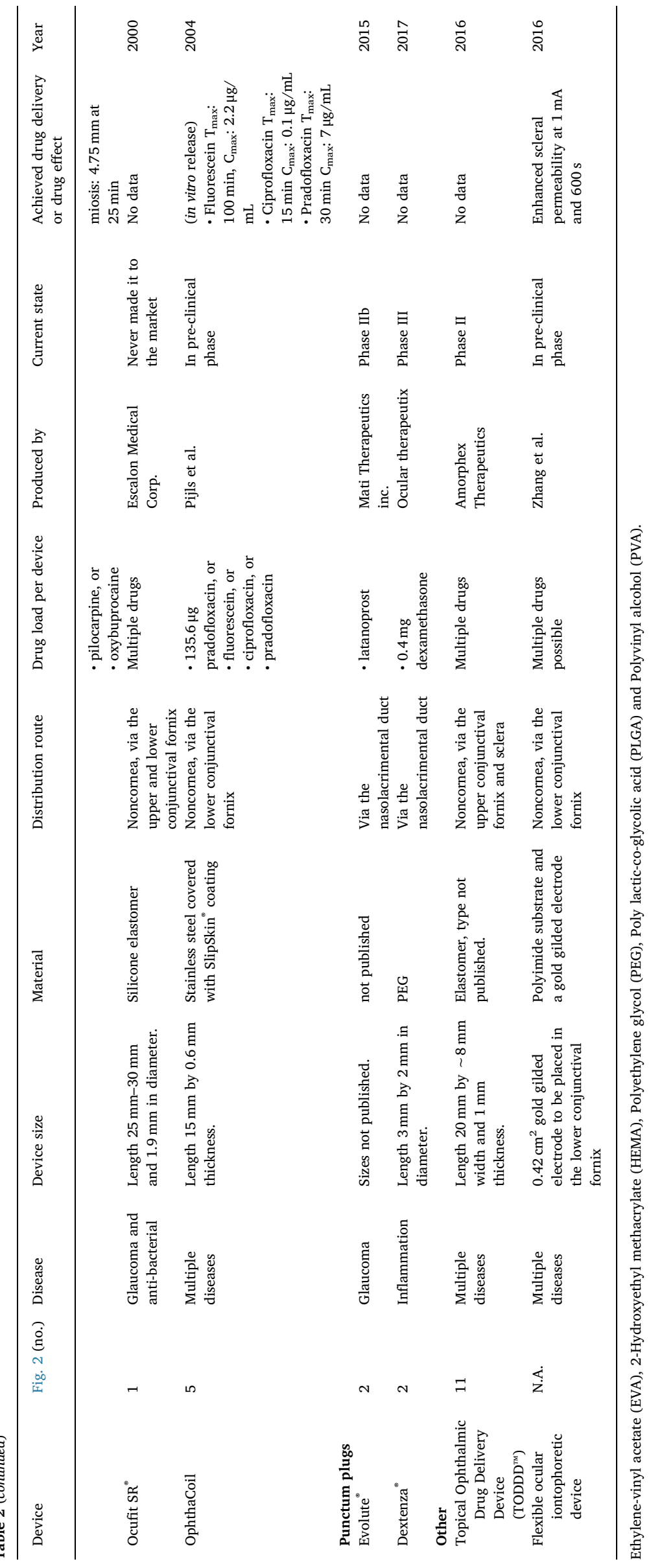


through the use of different formulations, such as microspheres (Fernandez-Sanchez et al., 2017), nanoparticles (Chiang et al., 2016), liposomes, micelles and prodrugs. These solutions are promising but do not guarantee higher patient compliance than eye drops (Cholkar et al., 2013; Gaudana et al., 2010; Kalita et al., 2014).

Finally, ocular treatments can be improved by better understanding the basic ocular and corneal pharmacokinetics (Chun et al., 2008; Ghate and Edelhauser, 2006; Mannermaa et al., 2006; Shirasaki, 2008; Urtti and Salminen, 1993). Therefore, fundamental research is indispensable and essential for the applied sciences.

In this review, we will cover resorbable devices, oval- and ringshaped devices, rod-shaped devices, punctum plugs, contact lenses and ocular shields. The characteristics of all these devices are summarized in Table 2.

\subsection{Resorbable conjunctival devices}

Resorbable drug delivery devices are devices which can be placed in the conjunctival sac and which dissolve and secrete drugs over time. The advantages of resorbable devices are that they are often non-invasive and do not need to be removed. However, most resorbable devices have a limited time of action (typically less than $24 \mathrm{~h}$ ) and thus may require frequent administration (Calles et al., 2015). Moreover, it is challenging to develop resorbable devices since the complete material and its metabolites should be non-toxic. Other challenges are the prevention of accidental loss of the device, which is not always noticed and the increase in tear production after placement which increases the risk of bulk release of drugs (Calles et al., 2015).

The only resorbable conjunctival device which is on the market is Lacrisert (Aton Pharma, Lawrenceville, New Jersey, USA) (Fig. 2,7). Lacrisert is a small hydroxypropyl cellulose tablet which has to be placed in the lower conjunctival fornix (Table 2). It slowly dissolves and creates an artificial tear film to treat dry eyes (Rajasekaran et al., 2010). However, Luchs et al. showed that wearing a Lacrisert insert can lead to blurred vision which warranted removal of the device in $8.7 \%$ of the participants (Luchs et al., 2010). Other known adverse effects related to wearing a Lacrisert ${ }^{\oplus}$ insert are ocular discomfort or ocular irritation because of foreign body sensations, stickiness of eyelashes, photophobia, hypersensitivity, eyelid edema, and hyperemia (Luchs et al., 2010; McDonald et al., 2010).

Another resorbable device called New Ophthalmic Delivery System (NODS ${ }^{\circ}$ ) was developed by Smith and Nephew Pharmaceuticals Ltd. (Gilston Park, Harlow, Essex, UK). The NODS ${ }^{\circ}$ is made from water-soluble polyvinyl alcohol (PVA) and should be placed in the cul-de-sac of the lower eyelid. The NODS ${ }^{\varpi}$ has been loaded with different drugs eg. pilocarpine, chloramphenicol and tropicamide (Sesha Rao et al., 2003). This device assured an eight-fold increase in drug bioavailability compared to eye drops in healthy volunteers (Diestelhorst and Krieglstein, 1994; Greaves et al., 1992; Saettone and Salminen, 1995). A small clinical trial with twelve volunteers revealed intense miosis in all test subjects as a side effect (Greaves et al., 1992). In a larger study with twenty-nine volunteers, there were some problems with the detachment of the NODS ${ }^{\circ}$ from its applicator (Diestelhorst and Krieglstein, 1994). Eventually, only the tropicamide loaded NODS ${ }^{\circ}$ was introduced into the market. Although the price was comparable to that of a tropicamide Minims (eye drops), the product was not commercially successful since it could only be used for diagnostic purposes (Sesha Rao et al., 2003). Therefore, many of the benefits, such as absence of preservative, improved bioavailability and convenience of storage were not relevant (Sesha Rao et al., 2003).

Another group investigated Gelfoam ${ }^{\circledR}$ discs (Pharmacia \& Upjohn Company LLC, Peapack, New Jersey, USA) as an alternative drug delivery system. The Gelfoam discs are made of resorbable gelatin and impregnated with insulin for diabetic patients or mydriatic drugs to widen the pupil. The Gelfoam discs should be placed in the lower conjunctival fornix and have been tested extensively in rabbits and human volunteers (Lee et al., 1999, 2002, 1997; Negvesky et al., 2000). Some volunteers $(6 / 20)$ developed a palpebral conjunctival infection (hyperemia), while other volunteers $(3 / 20)$ developed superficial punctate erosion (Negvesky et al., 2000). No further use of this device was reported.

\subsection{Oval- and ring-shaped conjunctival devices}

Several non-resorbable devices shaped as a ring or oval structure have been developed (Table 2). These devices are placed under the upper and/or lower eyelid in the conjunctival fornices and use the noncorneal route to distribute drugs.

One of the first breakthroughs within this field came from ALZA Corporation (Mountain View, California, USA) (acquired by Johnson \& Johnson, New Brunswick, New Jersey, USA in 2001). ALZA invented an oblong-shaped device (Fig. 2,8), called Ocusert ${ }^{\circ}$, which consisted of two ethylene-vinyl acetate (EVA) membranes filled with pilocarpine and covered by a ring of titanium dioxide impregnated EVA (Table 2) (Saettone and Salminen, 1995). The preferred location to place the Ocusert ${ }^{\oplus}$ was the upper conjunctival sac (Fig. 2,8b) and resulted in one week of drug delivery (Quigley et al., 1975). Ocusert came on the market in July 1974 and was available in two doses, the Ocusert Pilo20 (release of $20 \mu \mathrm{g} / \mathrm{h}$ ) and the Ocusert Pilo-40 (release of $40 \mu \mathrm{g} / \mathrm{h}$ ). However, the Ocusert ${ }^{\circ}$ was discontinued because of foreign body sensation, retention issues, difficulty in handling and only marginal IOP reduction (Kushnick et al., 1996; Langer, 1983; Mealy et al., 2014; Quigley et al., 1975; Saettone and Salminen, 1995). Because of these adverse effects and the low efficacy, the acceptance of Ocusert by the ophthalmic market was low (Langer, 1983; McGhee, 1992).

More recently, a polyethylene glycol (PEG) and polylactic-co-glycolic acid (PLGA) elliptical insert was created with a similar size and shape to the Ocusert ring. An in vitro study showed that the brimonidine tartrate-loaded insert produced a linear drug-release profile for one month. Further investigation is needed to demonstrate the potential of this drug-eluting device in the treatment of glaucoma (Mealy et al., 2014).

One particular example of a drug-loaded ring structure was developed by a Japanese research group. They developed a 2-hydroxyethyl methacrylate (HEMA) contact lens with a central hole. The device (loaded with $0.3 \%$ ofloxacin) could deliver ofloxacin to the anterior and even the posterior parts of the eye in rabbits. Drug delivery to the posterior part of the eye was achieved in 15-60 min after application of the device, via penetration of the conjunctiva and sclera into the choroid. Drug concentrations in the posterior tissue were more than ten times lower than those in the anterior tissue. However, compared to drug delivery from eye drops and corneal hydrogel lenses, drug concentrations in posterior tissue were ten to forty times higher, respectively (Shikamura et al., 2016).

A ring-shaped device $\left(\right.$ Helios $^{\mathrm{TM}}$ ) (Fig. 2,6) was developed by ForSight Vision5 Inc. (Menlo Park, California, USA). This ring (24-29 mm diameter, $1 \mathrm{~mm}$ thickness) consisted of an internal polypropylene support covered with bimatoprost-loaded silicone. The Helios ${ }^{\mathrm{TM}}$ ring had to be placed around the eye and can be used for the reduction of the IOP in glaucoma patients (Brandt et al., 2016; Higuchi et al., 1976). A phase II clinical trial (130 patients) demonstrated that the Helios ${ }^{\mathrm{TM}}$ ring reduced the IOP (4-6 mmHg) over a six month period. However, this IOP reduction was not significantly different when compared to regular unpreserved timolol $0.5 \%$ ophthalmic solution (Valeant Ophthalmics, Bridgewater, New Jersey, USA) (after 6 months a reduction of $3.25 \pm 0.32 \mathrm{mmHg}$ with bimatoprost compared to $4.24 \pm 0.37$ to timolol $0.5 \%$ ophthalmic solution). In addition, the drop-out rate was higher in the patient group with the Helios ${ }^{\mathrm{TM}}$ device ( 8 versus 2 in the eye drop group). (Brandt et al., 2016). A 13 month safety study (with a 6-month and 7-month interval) showed a safety profile consistent with bimatoprost exposure except for an increased incidence of eye discharge (mucus). The retention rate after 13 months was $94.7 \%$ 
suggesting that retention improves as patients gain more experience using the ring (Brandt et al., 2017).

\subsection{Rod-shaped conjunctival devices}

Another group of non-resorbable devices are the rod-shaped devices. These devices should also be placed in the upper or lower conjunctival fornix to deliver drugs via the non-corneal absorption route.

One small rod-shaped device that is available on the European market since 2004 is Mydriasert (Thea Laboratories, ClermontFerrand, France) Fig. 2,7, Table 2. Mydriasert ${ }^{\circledR}$ is an ethyl cellulose tablet which is loaded with tropicamide and phenylephrine hydrochloride to deliver mydriasis $2 \mathrm{~h}$ before surgery. However, when compared to topical mydriatic eye drops, there was no significant difference in pupil dilatation. In addition, topical mydriatic eye drops dilate the pupil faster (within $15 \mathrm{~min}$ ) compared to the Mydriasert ${ }^{\circ}$ insert (Cagini et al., 2014; Torron et al., 2013). The economic benefits of Mydriasert ${ }^{\bullet}$ were investigated in a cohort of 1763 patients in the U.K. Although an insert is more expensive compared to eye drops ( $£ 4.20$ per insert compared to $£ 0.41$ per vial for tropicamide $1 \%$ and $£ 0.49$ per vial of phenylephrine hydrochloride $10 \%$ ), nurse time could be decreased thereby saving $£ 1.20$ per patient. This resulted in a decrease of $18 \%$ in the total annual costs (Shah et al., 2015).

In the early nineties, the ophthalmic rod was developed (Alani, 1990; Alani and Hammerstein, 1990). This rod was intended as a singledose sterile applicator of drugs in order to avoid the problems of preservation, sterility, cross-infection and cross-contamination of eye drops. The non-toxic acrylic plastic rod could be loaded on one end with drugs (eg. tropicamide, oxybuprocaine, fluorescein or pilocarpine) by dipping the rod into an alcohol-drug solution. After evaporation of the alcohol, the drug-film could be used. The drugs were released in the lower conjunctiva by introducing the tip of the rod in the conjunctival sac and rubbing it against the palpebral conjunctiva of the lower lid. In this way, a small drug-film was created on the conjunctiva which was slowly dissolved by the tear film. The development of the rod was discontinued because of the induced mechanical stress on the tissue, drug preservation issues and the problem of its use in combination with other eye drops (Alani, 1990; Alani and Hammerstein, 1990).

Escalon Medical Corp. (Wayne, Pennsylvania, USA) patented Ocufit $\mathrm{SR}^{\circ}$, a drug-eluting rod-shaped ocular device which could be placed in the lower and upper conjunctival fornix (Fig. 2,1, Table 2) (Rajasekaran et al., 2010). The cylindrical rod was made of a silicone elastomer and loaded with drugs for the treatment of glaucoma or with antibiotics (Darougar, 1992; Saettone and Salminen, 1995). Although the placebo device could be retained in the upper fornix of the eye for over two weeks in 70\% of volunteers (Saettone and Salminen, 1995), the phase I study with the Ocufit $\mathrm{SR}^{\circ}$ device was discontinued in 2000 because of reallocation of the company's research and development interests (Newswire, 2000).

Finally, our group developed the OphthaCoil (Fig. 2,5 Table 2), a coiled stainless steel wire, which is placed in the lower conjunctival sac. The device can be filled with drugs inside its lumen (loaded on microspheres or filaments) or outside on the SlipSkin ${ }^{\varpi}$ coating (Dias et al., 2009; Duxfield et al., 2016; Pijls et al., 2004, 2005, 2006, 2007). The OphthaCoil was loaded with pradofloxacin and mydriatic agens (phenylephrine hydrochloride and tropicamide) and tested in Beagle dogs and horses. The pradofloxacin-loaded OphthaCoil resulted in drug delivery concentrations higher than the minimum inhibitory concentration (MIC) and the mydriatic-loaded OphthaCoil resulted in complete dilation $1 \mathrm{~h}$ after placement which lasted for one to $4 \mathrm{~h}$ after removal of the OphthaCoil (Pijls, 2007). Although tolerability of the OphthaCoil was excellent, the device was lost overnight in dogs and horses (probably because of the third eyelid, also called the nictitating membrane, which covers and protects the eyes during sleep). This is unlikely to occur in humans since humans do not have a third eyelid (Pijls et al., 2005).
In humans (pilot trials), short-term high tolerance and comfort of the device was demonstrated for a period of $2 \mathrm{~h}$ (Pijls, 2007; Pijls et al., 2004). Currently, new preclinical and clinical trials are being executed in order to further explore the potential of an ocular coil as an ocular drug delivery device for an extended period of time, up to 28 days.

\subsection{Punctum plugs}

Other types of ocular devices that show potential to be used as drug delivery devices are punctum plugs (Fig. 2,2, Table 2). These small plugs must be placed in the tear duct and were initially invented for patients with keratoconjunctivitis sicca (dry eye syndrome) (Chee, 2012; Driscoll and Blizzard, 2016; Yellepeddi et al., 2015). The first punctum plug used as an ocular drug delivery device was already developed in 1974 (Freeman, 1976).

In 2012 Mati Therapeutics (Austin, Texas, USA) and QLT Inc. (Vancouver, British Columbia, Canada) started collaborating in the field of punctum plugs (Lazar, 2011; Novelion, 2012; Odrich, 2005). They developed a latanoprost punctal plug delivery system (known as L-PPDS or Evolute ${ }^{\oplus}$ ) with a small drug reservoir in the head of the plug. After placement, the plug was able to deliver drugs via the lacrimal system into the tear film and to the tear duct (Muller and Utkhede, 2016). In 2015, a phase IIb multicenter trial was started to evaluate the efficacy of the L-PPDS. So far, no results or details have been reported (Business wire, 2015a,b).

Ocular Therapeutix Inc. (Bedford, Massachusetts, USA) developed Dextenza , a $0.4 \mathrm{mg}$ dexamethasone containing PEG punctum plug (Fig. 2.2 Table 2) for the treatment of inflammatory eye conditions up to 30 days after a cataract surgery. A phase II trial $(n=60)$ showed that Dextenza was effective in stopping itching and providing pain relief after cataract surgery (Walters et al., 2015). Another Phase II clinical trial in a group of 28 patients with allergic conjunctivitis (versus 31 patients in the vehicle group) showed improvement of allergic signs and symptoms in a 6 week trial. However, no significant difference in itching and ocular redness was observed between the Dextenza group and the vehicle group (Torkildsen et al., 2017). A phase III trial to demonstrate treatment of ocular itching associated with allergic conjunctivitis was also successful (Business wire, 2015a,b). Another phase III trial investigated the use of Dextenza ${ }^{\circ}$, for the treatment of ocular inflammation and pain after ophthalmic surgery (eg. cataract). Absence of anterior chamber cells and ocular pain on days 4, 14, and 30 after insertion of the insert was shown (Business wire, 2017). With these results, Ocular Therapeutix announced their intention to file a FDA new drug application (NDA) to bring their product to the market (Bethke, 2015; Business wire, 2015a,b; 2017; Cheema et al., 2016; Walters et al., 2015). In July 2017, the FDA rejected Ocular Therapeutix's NDA due to deficiencies in the manufacturing process and analytical testing identified during a pre-NDA approval inspection of an Ocular Therapeutix manufacturing facility (EyeWorld, 2017).

\subsection{Contact lenses and corneal shields}

Contact lenses and corneal shields have also been investigated for ocular drug delivery (Fig. 2,9). They are able to transport drugs via the corneal route, but must remain transparent in order to prevent vision loss. One potential advantage is that they could simultaneously deliver drugs and enhance vision by correcting the refractive error, After placement of a drug-loaded contact lens on the eye, the drug slowly diffuses into a thin fluid layer between the lens and the cornea, called the pre-ocular or post-lens tear film (POTF), and diffuses slowly through the surrounding tissues (via the cornea, limbus and conjunctiva) into the anterior segment of the eye (Creech et al., 2001; Li and Chauhan, 2006).

Since 1960, contact lenses and shields have been investigated to deliver drugs to the eye (Dixon et al., 2015; Jessen, 1964; Tian et al., 2001a, 2001b; Wichterle and Lim, 1960; Willoughby et al., 2002). Most 
of them were made by simply dipping the material (often a hydrogel) into a drug solution (Schultz and Morck, 2010). This 'soak and release' approach did not lead to a successful clinical product, mainly because of the short duration of release (Bengani et al., 2013). Currently, more innovative ways of drug-loading are being explored, for example by molecular imprinting or entrapping of nanoparticles into the polymer structure (Ali et al., 2007; Dixon et al., 2015; Li and Chauhan, 2006; Maulvi et al., 2016; Prakash and Dhesingh, 2017).

Although drug-loaded contact lenses result in an increased bioavailability of the drug over eye drops, and in silico and animal studies have proven safety and efficacy (Ali et al., 2007; Gause et al., 2016; Li and Chauhan, 2006), drug-eluting contact lenses have not yet reached the market. Contact lenses are associated with an increased risk of contact lens-related corneal damage and infections (Chalmers and Gleason, 2013; Konda et al., 2014; Richdale et al., 2016).

The following examples of drug-loaded contact lenses are promising: a latanoprost secreting PLGA contact lens developed by the department of Ophthalmology Massachusetts Eye and Ear Infirmary from Harvard Medical School (Boston, Massachusetts, USA), which was

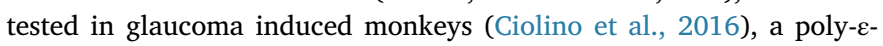
lysine (peK) hydrogel bandage lens containing amphotericin B for treatment of fungal keratitis which was tested in vitro, and is currently under development by the department of Eye and Vision Science, Institute of Ageing and Chronic Diseases from the University of Liverpool (Liverpool, UK) (Gallagher et al., 2017), and a brimonidine eluting thermosensitive hydrogel (consisting of PLGA-PEG-PLGA) with nanoparticles, which was developed by the department of Ophthalmology \& Visual Science and the Department of Pharmacy from the Eye \& ENT Hospital (Shanghai, China). This thermosensitive gel is applied between a soft contact lens and the cornea and was tested in vitro and in animals for its drug-secreting capacity (Sun et al., 2017). More contact lens and bandage lens related technologies are reviewed in (Maulvi et al., 2016; Papas, 2017; Zidan et al., 2017).

\subsection{Other devices}

Another example of a drug-delivery device with a particular shape has been developed by Amorphex Therapeutics (Dundee Park, Andover, Massachusetts, USA) (Table 2). The device called TODDD ${ }^{\mathrm{TM}}$ (Topical Ophthalmic Drug Delivery Device) is an 'eight-shaped' (Fig. 2,11) timolol or prostaglandin-containing elastomer $(20 \mathrm{~mm}$ length, about $8 \mathrm{~mm}$ width and $1 \mathrm{~mm}$ thickness) which should be placed on the sclera below the upper eyelid of glaucoma patients (Leahy and LaBombard, 2012). In a human trial, $(\mathrm{n}=20)$ the timolol-loaded device showed that the IOP was reduced by $16 \%-22 \%$ in glaucoma patients after 6 months (Bethke, 2015).

Finally, it is expected that a significant part of the population will have intraocular lenses (IOLs) implanted in the near future based on aging and extended life expectancies. So far, only few attempts have been made to use IOLs as drug delivery agents to prevent postoperative infection (Bouledjouidja et al., 2016; Mehta et al., 2015; Pimenta et al., 2017; Vieira et al., 2017) and inflammation (Bouledjouidja et al., 2016) or posterior capsule opacification, the most frequent complication of cataract surgery (Huang et al., 2013; Wertheimer et al., 2017). As far as we know, this has not resulted in commercial applications.

\section{Challenges in pharmacokinetics}

Ocular drug delivery devices have demonstrated improved drug uptake over conventional drug formulations. For example, higher uptake was measured through a corneal ring $(13 \mu \mathrm{g} / \mathrm{g}$ in the cornea and $4 \mu \mathrm{g} / \mathrm{mL}$ in the aqueous humour) (Shikamura et al., 2016), as compared to a topical solution $(6.95 \mu \mathrm{g} / \mathrm{g}$ in the cornea and $1.42 \mathrm{ng} / \mu \mathrm{g}$ in the aqueous humor) (Silva et al., 2017). However, besides on the delivery route, the level of drug uptake can be influenced significantly by a number of factors. Pharmacokinetics of eye drops can be improved by adapting the pH (affecting the logD7.4) (Del Amo et al., 2017) or adding additives to the formulation like frinstens benzalkonium chloride (BAC), that adds antimicrobial properties and enhances corneal permeability (Freeman and Kahook, 2014). According to some studies, EDTA enhances corneal penetration by chelation of calcium ions involved in opening of tight junctions (Ahuja et al., 2006; Grass et al., 1985; Morrison and Khutoryanskiy, 2014; Rojanasakul et al., 1990). Other studies however show no effect of EDTA in hydrophilic drugs (Pescina et al., 2016; Saettone et al., 1996) or lipophilic drugs (Grass et al., 1985; Kim et al., 2014; Madhu et al., 1996). Another enhancer for corneal permeability of lipophilic drugs is alpha cyclodextrin, which increases the solubility (Másson et al., 1999; Pescina et al., 2016). Enhanced uptake of drugs can also be achieved by esterified compounds which are often more lipophilic (Bito and Baroody, 1987). For example, compared to mice instilled with BAC enriched LA, aqueous humour concentrations of LA were five times higher in eyes of mice following treatment with LA and its choline ester (LACE) (Garner and Garner, 2016). Another example of an esterified drug is latanoprost (a prodrug from prostaglandin $\mathrm{F} 2 \mathrm{a}$ ) which increases uveoscleral outflow, thereby lowering the IOP by $20 \%-35 \%$ in patients with openangle glaucoma (Digiuni et al., 2012). Latanoprost was instilled in rabbits ( $30 \mu \mathrm{L}, 0.005 \%$ solution), which resulted in concentrations of $82 \pm 35 \mathrm{pg} / \mathrm{uL}$ in the aqueous humor $\left(\mathrm{T}_{\max } 1 \mathrm{~h}\right), 90 \pm 34 \mathrm{pg} / \mathrm{mg}$ in the conjunctiva ( $\left.\mathrm{T}_{\max } 15 \mathrm{~min}\right), 1202 \pm 576 \mathrm{pg} / \mathrm{mg}$ in the cornea $\left(\mathrm{T}_{\max }\right.$ $15 \mathrm{~min}$ ), and $264 \pm 157 \mathrm{pg} / \mathrm{mg}$ in the ciliary body ( $\mathrm{T}_{\max } 15 \mathrm{~min}$ ) (Daull et al., 2012). These concentrations are in line with results obtained in monkeys (Digiuni et al., 2012; Sjoquist et al., 1999). After topical $(50 \mu \mathrm{g} / \mathrm{mL})$ administration in humans, systemic latanoprost bioavailability was $45 \%$ with a maximum concentration $\left(\mathrm{C}_{\max }\right)$ of $53 \mathrm{pg} / \mathrm{mL}$ after $5 \mathrm{~min}\left(\mathrm{~T}_{\max }\right)$. About $88 \%$ of the available drug was recovered by the kidneys (Digiuni et al., 2012).

Besides additives and chemical modifications, oral supplementation of antioxidants in combination with topical nutraceutical components leads to decreased reactive oxygen species in the retina and lens, and enhances corneal permeability (Kador et al., 2014). Intravenous injections of the combretastatin A-4 prodrug (vascular disrupting agent) lead to effective drug concentrations for the prevention of neovascular agerelated macular degeneration in galactose-fed dogs (Kador et al., 2007) and in patients (Ibrahim et al., 2013).

Furthermore, pharmacokinetics can be altered due to eye rotations (Bonfiglio et al., 2015; Stocchino et al., 2007), ocular diseases (Guo et al., 2017; Ho et al., 2014; Li et al., 2016), ocular surgery (Cantor et al., 2007) and coating and modification of IOL materials (Bouledjouidja et al., 2016; Huang et al., 2013; Mehta et al., 2015; Pimenta et al., 2017; Wertheimer et al., 2017).

\section{Discussion and future prospectives}

The continuous increase in the number of ocular surgeries, combined with low patient compliance and low drug bioavailability, warrants the development of new drug delivery methods to the eye. Fortunately, progress has been made in recent years. Although conventional drug delivery formulations, such as eye drops and ointments, are easy to use, inexpensive new drug delivery devices should guarantee higher patient compliance and higher drug concentrations at the target site. Furthermore, drug treatments can be improved by combining next generation drug formulations (such as microspheres, nanoparticles and micelles) into the new drug delivery devices and by increasing fundamental knowledge on drug pharmacokinetics.

However, the public domain often lacks crucial information, in particular on achieved drug concentrations and effects in the various intraocular tissues. This may be due to the fact that companies are not keen on sharing proprietary information. Another major reason for the paucity of pharmacokinetic data of intraocular drug concentrations is that there are no non-invasive diagnostic methods to gather these data. Only invasive sampling at the time of surgery can be used or indirect 
ways of measuring drug effects, eg. measuring mydriasis when using dilating eye drops or drug delivery systems (see Table 2). This diagnostic measurement barrier makes it complex to compare new drug delivery devices to eye drops.

An important consideration with drug delivery devices is the shape of the device, since this is essential in terms of drug capacity, dislocation/retention and comfort. The question of which shape of device is most functional remains unanswered. In 1977 Katz et al. showed in a comparison study with 68 volunteers (128 rod-shaped devices and 127 oval-shaped devices) that rod-shaped devices were better tolerated compared to oval-shaped devices. Nevertheless, a number of devices of both shapes were lost after waking up by 'rubbing the sleep out of the eyes' (Katz and Blackman, 1977).

The idea of ocular ring structures was already patented in 1979 (U.S. 3,995,635 (Higuchi et al., 1976)) The Helios ${ }^{\mathrm{TM}}$ ring is visible whilst worn which puts forward the question of whether this is desirable from an aesthetic point of view. Other devices such as the TODDD ${ }^{\mathrm{Tm}}$ or the OphthaCoil are less visible since they are covered by the eyelids. Both devices are still in the developmental phase and there is no extensive data on retention and comfort outcome parameters in humans available yet. So far, an animal study showed that the OphthaCoil was not retained in dogs, most likely due to the animal's third eyelid (nictitating membrane). Similarly, dislocation of the Ocusert was described and was one of the reasons for market retrieval (Saettone and Salminen, 1995).

Contact lenses seem promising topical drug delivery devices. However, as they need to remain transparent and oxygen permeable (Papas, 2014) drug delivery via contact lenses is challenging. The newest advanced technologies (eg. nanoparticles (Garcia-Millan et al., 2017), micelles (Hu et al., 2016) and liposomes (Paradiso et al., 2017)) will help contact lenses to become another player in the drug delivery field.

Another way to deliver drugs is by a punctum plug, as currently executed by Ocular Therapeutix. During the first patent of the punctum plug, the possibility of ocular drug delivery was already covered (U.S. $3,949,750$ (Freeman, 1976)). Although punctum plugs have shown effective drug delivery up to six weeks (Torkildsen et al., 2017), they have a limited drug loading capacity due to their small size.

Despite these challenges in drug capacity, potential dislocation and discomfort, we believe that the trend towards using ocular devices for drug delivery is inevitable, as this may take away the daily burden of administration of eye drops. For cataract surgery the concept of "dropless cataract surgery", implying no use of eye drops around the surgical procedure anymore, has recently been introduced (Rhee and Mah, 2016).

Although the applied dose of drugs is often lower in the medical devices, the continuous and more stable release of drugs seems be more effective and more preferred by the tissues compared to the intervals with higher doses from eye drops (Brandt et al., 2016). Another advantage of ocular devices is the absence of preservatives and absorption enhancers. It is well known that these molecules (eg. benzalkonium chloride and EDTA) can have serious side-effects on the cornea and could eventually lead to the development of intolerable discomfort and allergies. Finally, decreased use of homecare for installation of eye drops in the elderly ophthalmic patient population will result in economic benefits (Shah et al., 2015).

With respect to the ophthalmic market, today there are only two conjunctival inserts available for 'non-invasive' drug delivery, i.e. Mydriasert $^{\odot}$ and Lacrisert $^{\odot}$. Although the new European Medical Device Regulation (MDR) will require more evidence on the effectiveness of new devices (for which patient compliance is pivotal, see Fig. 2), more inserts are expected to join the market in the following years. Also the FDA has recognized the need for new drug delivery devices for ocular use. The FDA now accepts first-in-human trials earlier and promised to simplify the approval process of new devices (Eydelman et al., 2016). This provides opportunities for researchers, ophthalmologists and the ophthalmic industry to realize the goal of improved ocular drug delivery. Only by working together (academia, industry and authorities) and by exploring parallel strategies (new drug delivery devices, enhanced drug formulations, better understanding of the pharmacokinetic properties), the therapeutic effect of drug treatments can be improved.

\section{Funding}

This research was performed under the framework of the Chemelot Institute for Science and Technology (InSciTe).

\section{Conflicts of interest}

The authors declare no conflict of interest.

\section{Acknowledgements}

The authors would like to thank Dr. Chris Duxbury for language editing and proofreading.

\section{References}

Agrahari, V., Mandal, A., Agrahari, V., Trinh, H.M., Joseph, M., Ray, A., Hadji, H., Mitra, R., Pal, D., Mitra, A.K., 2016. A comprehensive insight on ocular pharmacokinetics. Drug. Deliv. Transl. Res. 6, 735-754.

Ahmed, I., Patton, T.F., 1985. Importance of the noncorneal absorption route in topical ophthalmic drug delivery. Invest. Ophthalmol. Vis. Sci. 26, 584-587.

Ahuja, M., Dhake, A.S., Majumdar, D.K., 2006. Effect of formulation factors on in vitro permeation of diclofenac from experimental and marketed aqueous eye drops through excised goat cornea. Yakugaku Zasshi 126, 1369-1375.

Alani, S.D., 1990. The ophthalmic rod: a new ophthalmic drug delivery system I. Graefes Arch. Clin. Exp. Ophthalmol. 228, 297-301.

Alani, S.D., Hammerstein, W., 1990. The ophthalmic rod-a new drug-delivery system II. Graefes Arch. Clin. Exp. Ophthalmol. 228, 302-304.

Ali, M., Horikawa, S., Venkatesh, S., Saha, J., Hong, J.W., Byrne, M.E., 2007. Zero-order therapeutic release from imprinted hydrogel contact lenses within in vitro physiological ocular tear flow. J. Contr. Release 124, 154-162.

Ambati, J., Canakis, C.S., Miller, J.W., Gragoudas, E.S., Edwards, A., Weissgold, D.J., Kim, I., Delori, F.C., Adamis, A.P., 2000. Diffusion of high molecular weight compounds through sclera. Invest. Ophthalmol. Vis. Sci. 41, 1181-1185.

Bauer, N.J., Hendrikse, F., March, W.F., 1999a. In vivo confocal Raman spectroscopy of the human cornea. Cornea 18, 483-488.

Bauer, N.J., Motamedi, M., Wicksted, J.P., March, W.F., Webers, C.A., Hendrikse, F., 1999b. Non-invasive assessment of ocular pharmacokinetics using confocal Raman spectroscopy. J. Ocul. Pharmacol. Therapeut. 15, 123-134.

Bengani, L.C., Hsu, K.H., Gause, S., Chauhan, A., 2013. Contact lenses as a platform for ocular drug delivery. Expet Opin. Drug Deliv. 10, 1483-1496.

Bethke, W., 2015. New Frontiers in Sustained Release: an Update on the Most Viable Strategies for Releasing Glaucoma Drugs over Time. (accessed 28 June 2016), online. Review of Ophthalmology. https://www.reviewofophthalmology.com/article/newfrontiers-in-sustained-release.

Bito, L.Z., Baroody, R.A., 1987. The ocular pharmacokinetics of eicosanoids and their derivatives. 1 . comparison of ocular eicosanoid penetration and distribution following the topical application of PGF2 alpha, PGF2 alpha-1-methyl ester, and PGF2 alpha-1-isopropyl ester. Exp. Eye Res. 44, 217-226.

Bonfiglio, A., Lagazzo, A., Repetto, R., Stocchino, A., 2015. An experimental model of vitreous motion induced by eye rotations. Eye Vis (Lond) 2, 10.

Bouledjouidja, A., Masmoudi, Y., Sergent, M., Trivedi, V., Meniai, A., Badens, E., 2016. Drug loading of foldable commercial intraocular lenses using supercritical impregnation. Int. J. Pharm. 500, 85-99.

Bourne, W.M., 2003. Biology of the corneal endothelium in health and disease. Eye (Lond) 17, 912-918.

Brandt, J.D., DuBiner, H.B., Benza, R., Sall, K.N., Walker, G.A., Semba, C.P. Collaborators, 2017. Long-term safety and efficacy of a sustained-release bimatoprost ocular ring. Ophthalmology 124, 1565-1566.

Brandt, J.D., Sall, K., DuBiner, H., Benza, R., Alster, Y., Walker, G., Semba, C.P. Collaborators, 2016. Six-month intraocular pressure reduction with a topical bimatoprost ocular insert: results of a phase ii randomized controlled study. Ophthalmology 123, 1685-1694.

Business wire, 2015a. Mati Therapeutics Continues to Expand Patent Portfolio. Mat Therapeutics Inc (accessed 28 June 2016), online. http://www.businesswire.com/ news/home/20150506006399/en/Mati-Therapeutics-E\#.VVu_qJNVhBc.

Business wire, 2015b. Ocular Therapeutix ${ }^{\mathrm{TM}}$ Announces Topline Results of Phase 3 Clinical Trial for DEXTENZA ${ }^{\mathrm{TM}}$ for the Treatment of Allergic Conjunctivitis. Business wire (accessed 8 June 2016), online. http://www.businesswire.com/news/home/ 20151022006612/en/OcularTherapeutix\%E2\%84\%A2-Announces-Topline-ResultsPhase-3.

Business wire, 2017. Ocular Therapeutix ${ }^{\mathrm{TM}}$ Announces Additional Successful Results for 
Phase 3 Clinical Trial of DEXTENZA ${ }^{\mathrm{Tm}}$. Business wire (accessed: 9 January 2017), online. http://www.businesswire.com/news/home/20170104005445/en/OcularTherapeutix\%E2\%84\%A2-Announces-Additional-Successful-Results-Phase.

Cagini, C., Caricato, A., Tosi, G., Pascale, A., Cesari, C., Fiore, T., 2014. Evaluation of the efficacy and safety of the ophthalmic insert Mydriasert in patients undergoing retinal angiography. Eur. J. Ophthalmol. 24, 728-734.

Calles, J., Bermudez, J., Vallés, E., Allemandi, D., Palma, S., 2015. Polymers in ophthalmology. In: Puoci, F. (Ed.), Advanced Polymers in Medicine. Springer, Cham, pp. 147-176.

Cantor, L.B., Cioffi, G.A., Rapuano, C.J., 2014. In: Glaucoma, 2014-2015. American Academy of Ophthalmology, San Francisco, Calif.

Cantor, L.B., Hoop, J., Wudunn, D., Yung, C.W., Catoira, Y., Valluri, S., Cortes, A., Acheampong, A., Woodward, D.F., Wheeler, L.A., 2007. Levels of bimatoprost acid in the aqueous humour after bimatoprost treatment of patients with cataract. Br. J. Ophthalmol. 91, 629-632.

Carreon, T.A., Edwards, G., Wang, H., Bhattacharya, S.K., 2017. Segmental outflow of aqueous humor in mouse and human. Exp. Eye Res. 158, 59-66.

Chalmers, R.L., Gleason, W., 2013. Overview of contact lens postmarket surveillance in the United States: system and recent study results. Eye Contact Lens 39, 109-114.

Chee, S.P., 2012. Moxifloxacin punctum plug for sustained drug delivery. J. Ocul. Pharmacol. Therapeut. 28, 340-349.

Cheema, A., Chang, R.T., Shrivastava, A., Singh, K., 2016. Update on the medical treat ment of primary open-angle glaucoma. Asia Pac. J. Ophthalmol. (Phila) 5, 51-58.

Chiang, B., Venugopal, N., Edelhauser, H.F., Prausnitz, M.R., 2016. Distribution of particles, small molecules and polymeric formulation excipients in the suprachoroidal space after microneedle injection. Exp. Eye Res. 153, 101-109.

Cholkar, K., Patel, S.P., Vadlapudi, A.D., Mitra, A.K., 2013. Novel strategies for anterior segment ocular drug delivery. J. Ocul. Pharmacol. Therapeut. 29, 106-123.

Chun, D., Shapiro, A., Abelson, M., 2008. Ocular pharmacokinetics. In: Albert, D.M., Jakobiec, F.A. (Eds.), Principles and Practice of Ophthalmology, third ed. W.B. Saunders, Philadelphia, Pa.

Ciolino, J.B., Ross, A.E., Tulsan, R., Watts, A.C., Wang, R.F., Zurakowski, D., Serle, J.B., Kohane, D.S., 2016. Latanoprost-eluting contact lenses in glaucomatous monkeys. Ophthalmology 123, 2085-2092.

Creech, J.L., Chauhan, A., Radke, C.J., 2001. Dispersive mixing in the posterior tear film under a soft contact lens. Ind. Eng. Chem. Res. 40, 3015-3026.

Darougar, S., 1992. Ocular Insert for the Fornix. Nies, Kurz, Bergert \& Tamburro, USA, pp. 11.

Daull, P., Buggage, R., Lambert, G., Faure, M.O., Serle, J., Wang, R.F., Garrigue, J.S. 2012. A comparative study of a preservative-free latanoprost cationic emulsion (Catioprost) and a BAK-preserved latanoprost solution in animal models. J. Ocul. Pharmacol. Therapeut. 28, 515-523.

Del Amo, E.M., Rimpela, A.K., Heikkinen, E., Kari, O.K., Ramsay, E., Lajunen, T., Schmitt, M., Pelkonen, L., Bhattacharya, M., Richardson, D., Subrizi, A., Turunen, T., Reinisalo, M., Itkonen, J., Toropainen, E., Casteleijn, M., Kidron, H., Antopolsky, M., Vellonen, K.S., Ruponen, M., Urtti, A., 2017. Pharmacokinetic aspects of retinal drug delivery. Prog. Retin. Eye Res. 57, 134-185.

Del Amo, E.M., Urtti, A., 2008. Current and future ophthalmic drug delivery systems. A shift to the posterior segment. Drug Discov. Today 13, 135-143.

Del Amo, E.M., Urtti, A., 2015. Rabbit as an animal model for intravitreal pharmacokinetics: clinical predictability and quality of the published data. Exp. Eye Res. 137, 111-124.

Dias, A.J.A.A., Koole, L.H., Pijls, R.T., 2009. Coiled Wire for the Controlled Release of Drugs to the Eye. Google Patents, USA.

Diestelhorst, M., Krieglstein, G.K., 1994. The ocular tolerability of a new ophthalmic drug delivery system (NODS). Int. Ophthalmol. 18, 1-4.

Digiuni, M., Fogagnolo, P., Rossetti, L., 2012. A review of the use of latanoprost for glaucoma since its launch. Expet Opin. Pharmacother. 13, 723-745.

Dixon, P., Shafor, C., Gause, S., Hsu, K.H., Powell, K.C., Chauhan, A., 2015. Therapeutic contact lenses: a patent review. Expert Opin. Ther. Pat. 25, 1117-1129.

Driscoll, A., Blizzard, C., 2016. Toxicity and pharmacokinetics of sustained-release dex amethasone in beagle dogs. Adv. Ther. 33, 58-67.

Duxfield, L., Sultana, R., Wang, R., Englebretsen, V., Deo, S., Rupenthal, I.D., Al-Kassas, R., 2016. Ocular delivery systems for topical application of anti-infective agents. Drug Dev. Ind. Pharm. 42, 1-11.

Eaton, A.M., Gordon, G.M., Konowal, A., Allen, A., Allen, M., Sgarlata, A., Gao, G., Wafapoor, H., Avery, R.L., 2015. A novel eye drop application monitor to assess patient compliance with a prescribed regimen: a pilot study. Eye (Lond) 29, 1383-1391.

Edman, P., 1993. Biopharmaceutics of Ocular Drug Delivery. CRC Press, Boca Raton, Fla.

Edward, A., Prausnitz, M.R., 2001. Predicted permeability of the cornea to topical drugs. Pharm Res 18, 1497-1508.

Eydelman, M.B., Nguyen, T., Green, J.A., 2016. The US food and drug administration's new regulatory toolkit to bring medical device innovation back to the United States. JAMA Ophthalmol. 134, 353-354.

EyeWorld, 2017. FDA Rejects NDA for Ocular Therapeutix's Dexamethasone Insert. EyeWorld wkly Update 23 (accessed: 14 July 2017), online. http://campaign.r20. constantcontact.com/render? $\mathrm{m}=1108302654257 \& \mathrm{ca}=\mathrm{e} 9 \mathrm{~d} 64 \mathrm{~b} 47-5 \mathrm{ca} 4-46 \mathrm{c} 3-\mathrm{b} 104$ e3d4447adfb0.

Farkouh, A., Frigo, P., Czejka, M., 2016. Systemic side effects of eye drops: a pharmacokinetic perspective. Clin. Ophthalmol. 10, 2433-2441.

Fernandez-Sanchez, L., Bravo-Osuna, I., Lax, P., Arranz-Romera, A., Maneu, V., EstebanPerez, S., Pinilla, I., Puebla-Gonzalez, M.D.M., Herrero-Vanrell, R., Cuenca, N., 2017. Controlled delivery of tauroursodeoxycholic acid from biodegradable microspheres slows retinal degeneration and vision loss in P23H rats. PLoS One 12, e0177998.

Freeman, J.M., 1976. Punctum Plug and Method for Treating Keratoconjunctivitis Sicca
(Dry Eye) and Other Ophthalmic Aliments Using Same. Google Patents, USA, pp. 7.

Freeman, P.D., Kahook, M.Y., 2014. Preservatives in topical ophthalmic medications: historical and clinical perspectives. Expet Rev. Ophthalmol. 4, 59-64.

Gallagher, A.G., McLean, K., Stewart, R.M.K., Wellings, D.A., Allison, H.E., Williams, R.L., 2017. Development of a poly-epsilon-lysine contact lens as a drug delivery device for the treatment of fungal keratitis. Invest. Ophthalmol. Vis. Sci. 58, 4499-4505.

Garcia-Millan, E., Quintans-Carballo, M., Otero-Espinar, F.J., 2017. Improved release of triamcinolone acetonide from medicated soft contact lenses loaded with drug nanosuspensions. Int. J. Pharm. 525, 226-236.

Garner, W.H., Garner, M.H., 2016. Protein Disulfide levels and lens elasticity modulation: applications for presbyopia. Invest. Ophthalmol. Vis. Sci. 57, 2851-2863.

Gaudana, R., Ananthula, H.K., Parenky, A., Mitra, A.K., 2010. Ocular drug delivery. AAPS J. 12, 348-360.

Gause, S., Hsu, K.H., Shafor, C., Dixon, P., Powell, K.C., Chauhan, A., 2016. Mechanistic modeling of ophthalmic drug delivery to the anterior chamber by eye drops and contact lenses. Adv. Colloid Interface Sci. 233, 139-154.

Ghate, D., Edelhauser, H.F., 2006. Ocular drug delivery. Expet Opin. Drug Deliv. 3, 275-287.

Goel, M., Picciani, R.G., Lee, R.K., Bhattacharya, S.K., 2010. Aqueous humor dynamics: a review. Open Ophthalmol. J. 4, 52-59.

Grass, G.M., Wood, R.W., Robinson, J.R., 1985. Effects of calcium chelating agents on corneal permeability. Invest. Ophthalmol. Vis. Sci. 26, 110-113.

Greaves, J.L., Wilson, C.G., Birmingham, A.T., Richardson, M.C., Bentley, P.H., 1992. Scintigraphic studies on the corneal residence of a New Ophthalmic Delivery System (NODS): rate of clearance of a soluble marker in relation to duration of pharmacological action of pilocarpine. Br. J. Clin. Pharmacol. 33, 603-609.

Guo, T., Sampathkumar, S., Fan, S., Morris, N., Wang, F., Toris, C.B., 2017. Aqueous humour dynamics and biometrics in the ageing Chinese eye. Br. J. Ophthalmol. 101, 1290-1296.

Hermann, M.M., Ustundag, C., Diestelhorst, M., 2010. Electronic compliance monitoring of topical treatment after ophthalmic surgery. Int. Ophthalmol. 30, 385-390.

Higuchi, T., Hussain, A.A., Shell, J.W., 1976. In: Corporation, A. (Ed.), Ocular Insert. Google Patents, USA, pp. 6.

Ho, L.C., Conner, I.P., Do, C.W., Kim, S.G., Wu, E.X., Wollstein, G., Schuman, J.S., Chan, K.C., 2014. In vivo assessment of aqueous humor dynamics upon chronic ocular hypertension and hypotensive drug treatment using gadolinium-enhanced MRI. Invest. Ophthalmol. Vis. Sci. 55, 3747-3757.

Hu, X., Tan, H., Chen, P., Wang, X., Pang, J., 2016. Polymer micelles laden hydrogel contact lenses for ophthalmic drug delivery. J. Nanosci. Nanotechnol. 16 5480-5488.

Huang, X., Wang, Y., Cai, J.P., Ma, X.Y., Li, Y., Cheng, J.W., Wei, R.L., 2013. Sustained release of 5-fluorouracil from chitosan nanoparticles surface modified intra ocular lens to prevent posterior capsule opacification: an in vitro and in vivo study. J. Ocul. Pharmacol. Therapeut. 29, 208-215.

Hughes, P.M., Olejnik, O., Chang-Lin, J.E., Wilson, C.G., 2005. Topical and systemic drug delivery to the posterior segments. Adv. Drug Deliv. Rev. 57, 2010-2032.

Ibrahim, M.A., Do, D.V., Sepah, Y.J., Shah, S.M., Van Anden, E., Hafiz, G., Donahue, J.K., Rivers, R., Balkissoon, J., Handa, J.T., Campochiaro, P.A., Nguyen, Q.D., 2013. Vascular disrupting agent for neovascular age related macular degeneration: a pilot study of the safety and efficacy of intravenous combretastatin A-4 phosphate. BMC Pharmacol. Toxicol. 14, 7.

Jessen, G.N., 1964. Contact lenses as a therapeutic device. Am. J. Optom. Arch. Am. Acad. Optom. 41, 429-435.

Jick, S., 2016. In: Lens and Cataract, 2016-2017. American Academy of Ophthalmology, San Francisco, Calif.

Jonas, J.B., Aung, T., Bourne, R.R., Bron, A.M., Ritch, R., Panda-Jonas, S., 2017. Glaucoma. Lancet 390, 2183-2193.

Kador, P.F., Blessing, K., Randazzo, J., Makita, J., Wyman, M., 2007. Evaluation of the vascular targeting agent combretastatin a-4 prodrug on retinal neovascularization in the galactose-fed dog. J. Ocul. Pharmacol. Therapeut. 23, 132-142.

Kador, P.F., Guo, C., Kawada, H., Randazzo, J., Blessing, K., 2014. Topical nutraceutical optixcare EH ameliorates experimental ocular oxidative stress in rats. J. Ocul. Pharmacol. Therapeut. 30, 593-602.

Kalita, D., Shome, D., Jain, V.G., Chadha, K., Bellare, J.R., 2014. In vivo intraocular distribution and safety of periocular nanoparticle carboplatin for treatment of advanced retinoblastoma in humans. Am. J. Ophthalmol. 157, 1109-1115.

Katz, I.M., Blackman, W.M., 1977. A soluble sustained-release ophthalmic delivery unit. Am. J. Ophthalmol. 83, 728-734.

Kessel, L., Tendal, B., Jorgensen, K.J., Erngaard, D., Flesner, P., Andresen, J.L., Hjortdal, J., 2014. Post-cataract prevention of inflammation and macular edema by steroid and nonsteroidal anti-inflammatory eye drops: a systematic review. Ophthalmology 121 , 1915-1924.

Kidron, H., Del Amo, E.M., Vellonen, K.S., Urtti, A., 2012. Prediction of the vitreal halflife of small molecular drug-like compounds. Pharm. Res. 29, 3302-3311.

Kim, H., Robinson, M.R., Lizak, M.J., Tansey, G., Lutz, R.J., Yuan, P., Wang, N.S., Csaky, K.G., 2004. Controlled drug release from an ocular implant: an evaluation using dynamic three-dimensional magnetic resonance imaging. Invest. Ophthalmol. Vis. Sci. 45, 2722-2731.

Kim, S.J., Patel, S.N., Sternberg Jr., P., 2016. Routine use of nonsteroidal anti-inflammatory drugs with corticosteroids in cataract surgery: beneficial or redundant? Ophthalmology 123, 444-446.

Kim, S.J., Schoenberger, S.D., Thorne, J.E., Ehlers, J.P., Yeh, S., Bakri, S.J., 2015. Topical nonsteroidal anti-inflammatory drugs and cataract surgery: a report by the american academy of ophthalmology. Ophthalmology 122, 2159-2168.

Kim, Y.C., Chiang, B., Wu, X., Prausnitz, M.R., 2014. Ocular delivery of macromolecules. J. Contr. Release 190, 172-181. 
Konda, N., Motukupally, S.R., Garg, P., Sharma, S., Ali, M.H., Willcox, M.D., 2014. Microbial analyses of contact lens-associated microbial keratitis. Optom. Vis. Sci. 91, 47-53.

Kushnick, H., Liebmann, J.M., Ritch, R., 1996. Systemic pilocarpine toxicity from Ocusert leakage. Arch. Ophthalmol. 114, 1432.

Lang, J.C., 1995. Ocular drug-delivery conventional ocular formulations. Adv. Drug Deliv. Rev. 16, 39-43.

Langer, R., 1983. Implantable controlled release systems. Pharmacol. Ther. 21, 35-51.

Lavia, C., Dallorto, L., Maule, M., Ceccarelli, M., Fea, A.M., 2017. Minimally-invasive glaucoma surgeries (MIGS) for open angle glaucoma: a systematic review and metaanalysis. PLoS One 12, e0183142.

Lazar, E., 2011. Treatment Medium Delivery Device and Methods for Delivery of Such Treatment Mediums to the Eye Using Such a Delivery Device. OLT inc., USA, pp. 15.

Leahy, C.D., LaBombard, D., 2012. Ocular Drug Delivery Device. Vista Scientific LLC, USA, pp. 21.

Lee, S.B., Geroski, D.H., Prausnitz, M.R., Edelhauser, H.F., 2004. Drug delivery through the sclera: effects of thickness, hydration, and sustained release systems. Exp. Eye Res. 78, 599-607.

Lee, S.J., Kim, S.J., Kim, E.S., Geroski, D.H., McCarey, B.E., Edelhauser, H.F., 2008. Transscleral permeability of Oregon green 488. J. Ocul. Pharmacol. Therapeut. 24, 579-586.

Lee, Y.C., Millard, J., Negvesky, G.J., Butrus, S.I., Yalkowsky, S.H., 1999. Formulation and in vivo evaluation of ocular insert containing phenylephrine and tropicamide. Int. J. Pharm. 182, 121-126.

Lee, Y.C., Simamora, P., Pinsuwan, S., Yalkowsky, S.H., 2002. Review on the systemic delivery of insulin via the ocular route. Int. J. Pharm. 233, 1-18.

Lee, Y.C., Simamora, P., Yalkowsky, S.H., 1997. Systemic delivery of insulin via an enhancer-free ocular device. J Pharm Sci 86, 1361-1364.

Li, C.C., Chauhan, A., 2006. Modeling ophthalmic drug delivery by soaked contact lenses. Ind. Eng. Chem. Res. 45, 3718-3734.

Li, J., Lan, B., Li, X., Sun, S., Lu, P., Cheng, L., 2016. Effect of intraocular pressure (IOP) and choroidal circulation on controlled episcleral drug delivery to retina/vitreous. J. Contr. Release 243, 78-85.

Linn, M.L., Jones, L.T., 1968. Rate of lacrimal excretion of ophthalmic vehicles. Am. J. Ophthalmol. 65, 76-78.

Loewen, R.T., Brown, E.N., Roy, P., Schuman, J.S., Sigal, I.A., Loewen, N.A., 2016 Regionally discrete aqueous humor outflow quantification using fluorescein canalograms. PLoS One 11, e0151754.

Luchs, J.I., Nelinson, D.S., Macy, J.I., Group, L.A.C.S., 2010. Efficacy of hydroxypropyl cellulose ophthalmic inserts (LACRISERT) in subsets of patients with dry eye syndrome: findings from a patient registry. Cornea 29, 1417-1427.

Madhu, C., Rix, P.J., Shackleton, M.J., Nguyen, T.G., Tang-Liu, D.D., 1996. Effect of benzalkonium chloride/EDTA on the ocular bioavailability of ketorolac tromethamine following ocular instillation to normal and de-epithelialized corneas of rabbits. J Pharm Sci 85, 415-418.

Maichuk, Y.F., 1975a. Editorial: ophthalmic drug inserts. Invest. Ophthalmol. 14, 87-90.

Maichuk, Y.F., 1975b. Letter: soluble ophthalmic drug inserts. Lancet 1, 173.

Makley, L.N., McMenimen, K.A., DeVree, B.T., Goldman, J.W., McGlasson, B.N., Rajagopal, P., Dunyak, B.M., McQuade, T.J., Thompson, A.D., Sunahara, R., Klevit, R.E., Andley, U.P., Gestwicki, J.E., 2015. Pharmacological chaperone for alphacrystallin partially restores transparency in cataract models. Science 350, 674-677.

Mannermaa, E., Vellonen, K.S., Urtti, A., 2006. Drug transport in corneal epithelium and blood-retina barrier: emerging role of transporters in ocular pharmacokinetics. Adv. Drug Deliv. Rev. 58, 1136-1163.

Másson, M., Loftsson, T., Másson, G.s., Stefánsson, E., 1999. Cyclodextrins as permeation enhancers: some theoretical evaluations and in vitro testing. J. Contr. Release 59, 107-118.

Maulvi, F.A., Soni, T.G., Shah, D.O., 2016. A review on therapeutic contact lenses for ocular drug delivery. Drug Deliv. 23, 3017-3026.

McDonald, M., D'Aversa, G., Perry, H.D., Wittpenn, J.R., Nelinson, D.S., 2010. Correlating patient-reported response to hydroxypropyl cellulose ophthalmic insert (LACRISERT(R)) therapy with clinical outcomes: tools for predicting response. Curr. Eye Res. 35, 880-887.

McGhee, C.N., 1992. Pharmacokinetics of ophthalmic corticosteroids. Br. J. Ophthalmol. $76,681-684$.

Mealy, J.E., Fedorchak, M.V., Little, S.R., 2014. In vitro characterization of a controlledrelease ocular insert for delivery of brimonidine tartrate. Acta Biomater. 10, 87-93.

Mehta, P., Justo, L., Walsh, S., Arshad, M.S., Wilson, C.G., O'Sullivan, C.K., Moghimi, S.M., Vizirianakis, I.S., Avgoustakis, K., Fatouros, D.G., Ahmad, Z., 2015. New platforms for multi-functional ocular lenses: engineering double-sided functionalized nano-coatings. J. Drug Target. 23, 305-310.

Mohindroo, C., Ichhpujani, P., Kumar, S., 2015. How 'Drug Aware' are our glaucoma patients? J. Curr. Glaucoma Pract. 9, 33-37.

Morrison, P.W., Khutoryanskiy, V.V., 2014. Enhancement in corneal permeability of riboflavin using calcium sequestering compounds. Int. J. Pharm. 472, 56-64.

Muller, C., Utkhede, D., 2016. Therapy without drops: a reality. ONdrugDel 36.

Negvesky, G.J., Butrus, S.I., Abifarah, H.A., Lee, Y.C., Yalkowsky, S.H., 2000. Ocular gelfoam disc-applicator for pupillary dilation in humans. J. Ocul. Pharmacol. Therapeut. 16, 311-315.

Newman-Casey, P.A., Robin, A.L., Blachley, T., Farris, K., Heisler, M., Resnicow, K., Lee, P.P., 2015. The most common barriers to glaucoma medication adherence: a crosssectional survey. Ophthalmology 122, 1308-1316.

Newswire, P., 2000. Escalon(R) Medical Corp. Acquires Sonomed Discontinues Clinical Trial of Ocufit SR(R). pr newswire (accessed: 14 July 2016), online. http://www. prnewswire.com/news-releases/escalonr-medical-corp-acquires-sonomeddiscontinues-clinical-trial-of-ocufit-srr-72104557.html.
Nordmann, J.P., Baudouin, C., Renard, J.P., Denis, P., Lafuma, A., Laurendeau, C., Jeanbat, V., Berdeaux, G., 2010. Measurement of treatment compliance using a medical device for glaucoma patients associated with intraocular pressure control: a survey. Clin. Ophthalmol. 4, 731-739.

Novelion, 2012. QLT Announces Exclusive Option Agreement for Potential Sale of Punctal Plug Delivery System. (accessed: 24 May 2016), online. http://ir.novelion.com/ releasedetail.cfm? releaseid $=995645$.

Odrich, S., 2005. Drug Delivery via Punctal Plug. Google Patents, USA, pp. 5.

Palmer, R.M., Kaufman, H.E., 1995. Tear film, pharmacology of eye drops, and toxicity. Curr. Opin. Ophthalmol. 6, 11-16.

Papas, E.B., 2014. The significance of oxygen during contact lens wear. Contact Lens Anterior Eye: J. Br. Contact Lens Assoc. 37, 394-404.

Papas, E.B., 2017. Contact lens technology to 2020 and beyond: a review of recent patent literature. Clin. Exp. Optom. 100, 529-536.

Paradiso, P., Colaco, R., Mata, J.L.G., Krastev, R., Saramago, B., Serro, A.P., 2017. Drug release from liposome coated hydrogels for soft contact lenses: the blinking and temperature effect. Journal of biomedical materials research. Part B, Appl. biomat. 105, 1799-1807.

Pelkonen, L., Tengvall-Unadike, U., Ruponen, M., Kidron, H., Del Amo, E.M., Reinisalo, M., Urtti, A., 2017. Melanin binding study of clinical drugs with cassette dosing and rapid equilibrium dialysis inserts. Eur. J. Pharmaceut. Sci. 109, 162-168.

Pescina, S., Carra, F., Padula, C., Santi, P., Nicoli, S., 2016. Effect of pH and penetration enhancers on cysteamine stability and trans-corneal transport. Eur. J. Pharm. Biopharm. 107, 171-179.

Pijls, R.T., 2007. The OPHTHACoil, a new vehicle for the delivery of drugs to the eye. Ophthalmology 1591 ed.. Wöhrmann Print Service, Maastricht.

Pijls, R.T., Cruysberg, L.P., Nuijts, R.M., Dias, A.A., Koole, L.H., 2007. Capacity and tolerance of a new device for ocular drug delivery. Int. J. Pharm. 341, 152-161.

Pijls, R.T., Hanssen, H.H., Nuijts, R.M., Daube, G.W., Koole, L.H., 2006. In vivo tolerance and kinetics of a novel ocular drug delivery device. J. Contr. Release 116, e47-49.

Pijls, R.T., Hanssen, H.H., Nuijts, R.M., Koole, L.H., 2004. Flexible coils with a drugreleasing hydrophilic coating: a new platform for controlled delivery of drugs to the eye? Bio Med. Mater. Eng. 14, 383-393.

Pijls, R.T., Sonderkamp, T., Daube, G.W., Krebber, R., Hanssen, H.H., Nuijts, R.M., Koole, L.H., 2005. Studies on a new device for drug delivery to the eye. Eur. J. Pharm. Biopharm. 59, 283-288.

Pimenta, A.F.R., Vieira, A.P., Colaco, R., Saramago, B., Gil, M.H., Coimbra, P., Alves, P., Bozukova, D., Correia, T.R., Correia, I.J., Guiomar, A.J., Serro, A.P., 2017. Controlled release of moxifloxacin from intraocular lenses modified by Ar plasma-assisted grafting with AMPS or SBMA: an in vitro study. Colloids Surf. B Biointer. 156, 95-103.

Prakash, M., Dhesingh, R.S., 2017. Nanoparticle modified drug loaded biodegradable polymeric contact lenses for sustainable ocular drug delivery. Curr. Drug Deliv. 14, $555-565$.

Pucker, A.D., Ng, S.M., Nichols, J.J., 2016. Over the counter (OTC) artificial tear drops for dry eye syndrome. Cochrane Database Syst. Rev. 2, CD009729.

Quigley, H.A., Pollack, I.P., Harbin Jr., T.S., 1975. Pilocarpine ocuserts. long-term clinical trials and selected pharmacodynamics. Arch. Ophthalmol. 93, 771-775.

Rajasekaran, A., Ardul Kumaran, K., Karthika, K., Padma preetha, J., 2010. A comparative review on conventional and advanced ocular drug delivery formulations. Int. J. Pharm. Tech. Res. 2, 668-674.

Rhee, M.K., Mah, F.S., 2016. Cataract drug delivery systems (Dropless vs. Nondropless Cataract Surgery). Int. Ophthalmol. Clin. 56, 117-136.

Richdale, K., Lam, D.Y., Wagner, H., Zimmerman, A.B., Kinoshita, B.T., Chalmers, R., Sorbara, L., Szczotka-Flynn, L., Govindarajulu, U., Mitchell, G.L., 2016. Case-control pilot study of soft contact lens wearers with corneal infiltrative events and healthy controls. Invest. Ophthalmol. Vis. Sci. 57, 47-55.

Rojanasakul, Y., Liaw, J., Robinson, J.R., 1990. Mechanisms of action of some penetration enhancers in the cornea: laser scanning confocal microscopic and electrophysiology studies. Int. J. Pharm. 66, 131-142.

Saettone, M.F., Chetoni, P., Cerbai, R., Mazzanti, G., Braghiroli, L., 1996. Evaluation of ocular permeation enhancers: in vitro effects on corneal transport of four $\beta$-blockers, and in vitro/in vivo toxic activity. Int. J. Pharm. 142, 103-113.

Saettone, M.F., Salminen, L., 1995. Ocular inserts for topical delivery. Adv. Drug Deliv. Rev. 16, 95-106.

Salyani, A., Birt, C., 2005. Evaluation of an eye drop guide to aid self-administration by patients experienced with topical use of glaucoma medication. Can. J. Ophthalmol. 40, 170-174.

Schultz, C.L., Morck, D.W., 2010. Contact lenses as a drug delivery device for epidermal growth factor in the treatment of ocular wounds. Clin. Exp. Optom. 93, 61-65.

Sesha Rao, L., Rathbone, M.J., Hadgraft, J., Roberts, M.S., 2003. Modified-release Drug Delivery Technology, Drugs and the Pharmaceutical Sciences. Marcel Dekker, New York, pp. 329-340.

Shah, A., Johal, S., Lee, N., 2015. Mydriasert pupillary dilation for cataract surgery: an economic and clinical study. BMC Ophthalmol. 15, 56.

Shah, N., Maguire, M.G., Martin, D.F., Shaffer, J., Ying, G.S., Grunwald, J.E., Toth, C.A. Jaffe, G.J., Daniel, E., Comparison of age-related macular degeneration treatments trials research, G., 2016. Angiographic cystoid macular edema and outcomes in the comparison of age-related macular degeneration treatments trials. Ophthalmology $123,858-864$.

Shikamura, Y., Yamazaki, Y., Matsunaga, T., Sato, T., Ohtori, A., Tojo, K., 2016. Hydrogel ring for topical drug delivery to the ocular posterior segment. Curr. Eye Res. 41, 653-661.

Shirasaki, Y., 2008. Molecular design for enhancement of ocular penetration. J. Pharm. Sci. $97,2462-2496$.

Silva, G.C.M., Jabor, V.A.P., Bonato, P.S., Martinez, E.Z., Faria, E.S.S.J., 2017. Penetration 
of $0.3 \%$ ciprofloxacin, $0.3 \%$ ofloxacin, and $0.5 \%$ moxifloxacin into the cornea and aqueous humor of enucleated human eyes. Braz. J. Med. Biol. Res. 50, e5901.

Sjoquist, B., Johansson, A., Stjernschantz, J., 1999. Pharmacokinetics of latanoprost in the cynomolgus monkey. 3rd communication: tissue distribution after topical administration on the eye studied by whole body autoradiography. Glaucoma Res. Lab. Arzneimittelforschung 49, 240-249.

Stocchino, A., Repetto, R., Cafferata, C., 2007. Eye rotation induced dynamics of a Newtonian fluid within the vitreous cavity: the effect of the chamber shape. Phys. Med. Biol. 52, 2021-2034.

Sun, J., Lei, Y., Dai, Z., Liu, X., Huang, T., Wu, J., Xu, Z.P., Sun, X., 2017. Sustained release of brimonidine from a new composite drug delivery system for treatment of glaucoma. ACS Appl. Mater. Interfaces 9, 7990-7999.

Tan, D.T., Chee, S.P., Lim, L., Lim, A.S., 1999. Randomized clinical trial of a new dexamethasone delivery system (Surodex) for treatment of post-cataract surgery inflammation. Ophthalmology 106, 223-231.

Tan, D.T., Chee, S.P., Lim, L., Theng, J., Van Ede, M., 2001. Randomized clinical trial of Surodex steroid drug delivery system for cataract surgery: anterior versus posterior placement of two Surodex in the eye. Ophthalmology 108, 2172-2181.

Tian, X., Iwatsu, M., Kanai, A., 2001a. Disposable 1-day Acuvue contact lenses for the delivery of lomefloxacin to rabbits' eyes. CLAO J. 27, 212-215.

Tian, X., Iwatsu, M., Sado, K., Kanai, A., 2001b. Studies on the uptake and release of fluoroquinolones by disposable contact lenses. CLAO J. 27, 216-220.

Torkildsen, G., Abelson, M.B., Gomes, P.J., McLaurin, E., Potts, S.L., Mah, F.S., 2017. Vehicle-controlled, phase 2 clinical trial of a sustained-release dexamethasone intracanalicular insert in a chronic allergen challenge model. J. Ocul. Pharmacol. Therapeut. 33, 79-90.

Torron, C., Calvo, P., Ruiz-Moreno, O., Lecinena, J., Perez-Inigo, A., 2013. Use of a new ocular insert versus conventional mydriasis in cataract surgery. BioMed Res. Int. 2013, 849349.

Trese, M.G.J., Lewis, A.W., Blachley, T.S., Stein, J.D., Moroi, S.E., 2017. Changing initial glaucoma medical therapy increases healthcare resource utilization. J. Ocul. Pharmacol. Therapeut. 33, 591-597.

Urtti, A., Salminen, L., 1985. Concentration-dependent precorneal loss of pilocarpine in rabbit eyes. Acta Ophthalmol (Copenh) 63, 502-506.

Urtti, A., Salminen, L., 1993. Minimizing systemic absorption of topically administered ophthalmic drugs. Surv. Ophthalmol. 37, 435-456.

Vellonen, K.S., Soini, E.M., Del Amo, E.M., Urtti, A., 2016. Prediction of ocular drug distribution from systemic blood circulation. Mol. Pharm. 13, 2906-2911.
Vieira, A.P., Pimenta, A.F.R., Silva, D., Gil, M.H., Alves, P., Coimbra, P., Mata, J., Bozukova, D., Correia, T.R., Correia, I.J., Serro, A.P., Guiomar, A.J., 2017. Surface modification of an intraocular lens material by plasma-assisted grafting with 2-hydroxyethyl methacrylate (HEMA), for controlled release of moxifloxacin. Eur. J. Pharm. Biopharm. 120, 52-62.

Walters, T., Endl, M., Elmer, T.R., Levenson, J., Majmudar, P., Masket, S., 2015. Sustained-release dexamethasone for the treatment of ocular inflammation and pain after cataract surgery. J. Cataract Refract. Surg. 41, 2049-2059.

Wertheimer, C., Kassumeh, S., Piravej, N.P., Nilmayer, O., Braun, C., Priglinger, C., Luft, N., Wolf, A., Mayer, W.J., Priglinger, S.G., Eibl-Lindner, K.H., 2017. The intraocular lens as a drug delivery device: in vitro screening of pharmacologic substances for the prophylaxis of posterior capsule opacification. Invest. Ophthalmol. Vis. Sci. 58, 6408-6418.

Wichterle, O., Lim, D., 1960. Hydrophilic gels for biological use. Nature 185, 117-118.

Wielders, L.H., Lambermont, V.A., Schouten, J.S., van den Biggelaar, F.J., Worthy, G., Simons, R.W., Winkens, B., Nuijts, R.M., 2015. Prevention of cystoid macular edema after cataract surgery in nondiabetic and diabetic patients: a systematic review and meta-analysis. Am. J. Ophthalmol. 160, 968-981 e933.

Wielders, L.H., Schouten, J.S., Aberle, M.R., Lambermont, V.A., van den Biggelaar, F.J., Winkens, B., Simons, R.W., Nuijts, R.M., 2017. Treatment of cystoid macular edema after cataract surgery. J. Cataract Refract. Surg. 43, 276-284.

Willoughby, C.E., Batterbury, M., Kaye, S.B., 2002. Collagen corneal shields. Surv. Ophthalmol. 47, 174-182.

Yellepeddi, V.K., Sheshala, R., McMillan, H., Gujral, C., Jones, D., Raghu Raj Singh, T., 2015. Punctal plug: a medical device to treat dry eye syndrome and for sustained drug delivery to the eye. Drug Discov. Today 20, 884-889.

Zhang, W., Prausnitz, M.R., Edwards, A., 2004. Model of transient drug diffusion across cornea. J. Contr. Release 99, 241-258.

Zhao, L., Chen, X.J., Zhu, J., Xi, Y.B., Yang, X., Hu, L.D., Ouyang, H., Patel, S.H., Jin, X., Lin, D., Wu, F., Flagg, K., Cai, H., Li, G., Cao, G., Lin, Y., Chen, D., Wen, C., Chung, C., Wang, Y., Qiu, A., Yeh, E., Wang, W., Hu, X., Grob, S., Abagyan, R., Su, Z., Tjondro, H.C., Zhao, X.J., Luo, H., Hou, R., Jefferson, J., Perry, P., Gao, W., Kozak, I., Granet, D., Li, Y., Sun, X., Wang, J., Zhang, L., Liu, Y., Yan, Y.B., Zhang, K., 2015. Lanosterol reverses protein aggregation in cataracts. Nature 523, 607-611.

Zidan, G., Rupenthal, I.D., Greene, C., Seyfoddin, A., 2017. Medicated ocular bandages and corneal health: potential excipients and active pharmaceutical ingredients. Pharmaceut. Dev. Technol. 1-6. 